\title{
ELECTROCHEMICAL BEHAVIOUR OF ANTHRAQUINONE DYES IN NON AQUEOUS SOLVENT SOLUTION.
}

\section{Part I. Medium effect on the electrochemical behaviour}

\author{
J.A. Caram ${ }^{\text {a }}$ M.J. Banera ${ }^{\text {a, b }}$, J.F. Martínez Suárez ${ }^{\text {a }}$ M.V. Mirífico ${ }^{\text {a, b, * }}$ \\ a Instituto de Investigaciones Fisicoquímicas Teóricas y Aplicadas (INIFTA), CCT La Plata, Casilla de Correo 16, Sucursal 4, 1900 La Plata, Argentina. \\ ${ }^{\mathrm{b}}$ Facultad de Ingeniería, Departamento de Ingeniería Química, Universidad Nacional de La Plata, Calle 47 y 1, 1900 La Plata, Argentina.
}

\section{A R T I C L E IN F O}

\section{Article history:}

Received 31 May 2017

Received in revised form 20 July 2017

Accepted 24 July 2017

Available online $\mathrm{xxx}$

Keywords:

Alizarin

UV-Vis

Supporting electrolyte effect

Solvent effect

Electrode reaction mechanism

\begin{abstract}
A B S T R A C T
The conditions under which alizarin, purpurin, carminc acid, quinalizarin and alizarin red $\mathrm{S}$ in the solution of several organic solvents can be electrochemically transformed are analysed. The electrochemical activity of these molecules with quinone and phenolic moieties is relatively easy detected by cyclic voltammetry. Numerous electro-reduction/oxidation processes without and with added acid or base are observed. The number, the current intensity and the peak potential of the charge transfer processes are rationalized on the basis of the homogeneous dissociation equilibriums of the phenolic-OH groups. These equilibria are significantly altered by the medium. A supporting electrolyte unexpected and important effect on the electrochemical behaviour is observed. Alkaline cation of the supporting electrolyte promotes the changes in the electrochemical behaviour by coordinating with opposite charge species. A confusion published in the literature that the electro-reduction of the hydroxyquinones proceeds only through the formation of a radical-anion and a dianion is revealed. Solvent effect is explained by the stabilization of charge species, which is related to some solvent properties (Gutmann acceptor/donor number and dielectric constant). Solvents with strong acceptor properties favour the dissociation of the phenolic-OH groups. The dissociation equilibriums of phenolic-OH groups in each solvent are confirmed by UV-vis spectra of each dye in solution. Alizarin in DMA solvent with added base shows a particular electrochemical behaviour.
\end{abstract}

For alizarin/DMF system a reaction mechanism is proposed, and alternative mechanisms are suggested for other dyes.

\section{INTRODUCTION}

Natural dyes were employed since ancient times. For centuries, these substances were the only dyes used to change the colour of numerous materials. However, synthetic dye industry is at present one of the most important. The use of many of these synthetic chemicals that are employed to colour food, drugs, cosmetics and clothing has been restricted by the high toxicity of some of them [1]. Environmental issues in the production and application of synthetic dyes once again revived consumer interest in natural dyes and their derivatives. The natural dyes derived from 9,10-anthraquinone have a leading role due to the relative abundance and possibilities of transformations that they offer [2]. Dyes containing 9,10-anthraquinone moiety and its derivatives are among the most resistant to light-induced fading $[3,4]$. Anthraquinone derivatives in general are also known as analytical reagents [5-8], and are currently investigated as promising redox materials for next generation batteries $[9,10]$.

\footnotetext{
* Corresponding author at: Instituto de Investigaciones Fisicoquímicas Teóricas y Aplicadas (INIFTA), CCT La Plata, Casilla de Correo 16, Sucursal 4, 1900 La Plata, Argentina. Tel.: +54 221425 7430/7291

Email address: mirifi@inifta.unlp.edu.ar, mirifi@live.com.ar (M.V. Mirífico)
}

The most common natural anthraquinone derivatives are alizarin (1,2-dihydroxy-9,10-anthracenedione, ALZ), purpurine (1,2,4-trihydroxyanthracene-9,10-dione, PP), and carminic acid (3,5,6,8-tetrahydroxy-1-methyl-9,10-dioxo-7-[3,4,5-trihydroxy-6-(hydroxymethyl)oxan-2-yl]anthracene-2-carboxylic acid, CA) (Scheme 1). In addition to the natural dyes, there are synthetic colourants of similar characteristics such as quinalizarin (1,2,5,8-tetrahydroxyanthracene-9,10-dione, QZ), and alizarin red S (9,10-dihydro-3,4-dihydroxy-9,10-dioxo-2-anthracenesulfonic acid, sodium salt, ALS) (Scheme 1).

Hydroxyanthraquinones present a long list of possible applications related to their interesting photoactivity. Most applications are based in their chromatic properties. Their colours depend on the position and number of the hydroxyl substituents [11]. Alizarin exists in three forms of different colours, namely the protonated species (neutral non-dissociated $\mathrm{AH}_{2}$ in Scheme 2) and two deprotonated species corresponding to the monoanion $\left(\mathrm{AH}^{-}\right.$in Scheme 2$)$ and dianion $\left(\mathrm{A}^{2-}\right.$ in Scheme 2). The absorption maximum of the neutral non-dissociated form is located at $430 \mathrm{~nm}$, the monoanionic form is characterized by an absorption maximum at around $530 \mathrm{~nm}$ while the dianionic form is represented by two superimposed bands in the range from $570 \mathrm{~nm}$ to $620 \mathrm{~nm}$ [11-17]. The colour change of alizarin is modelled based on simple protocol within TD-DFT framework [13]. 
<smiles>O=C1c2ccccc2C(=O)c2c1ccc(O)c2O</smiles>

ALIZARIN (ALZ)<smiles>Cc1c(C(=O)O)c(O)cc2c1C(=O)c1c(O)c([C@H]3OC[C@@H](O)[C@H](O)[C@H]3O)c(O)c(O)c1C2=O</smiles>

CARMINIC ACID (CA)

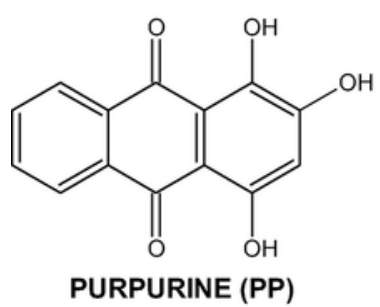<smiles>O=C1c2ccc(O)c(O)c2C(=O)c2c(O)ccc(O)c21</smiles>

QUINALIZARIN (QZ)<smiles>O=C1c2ccccc2C(=O)c2c1cc(S(=O)(=O)O)c(O)c2O</smiles>

ALIZARIN RED S (ALS)

Scheme 1. Structural formulas of the 9,10-anthraquinone dyes.

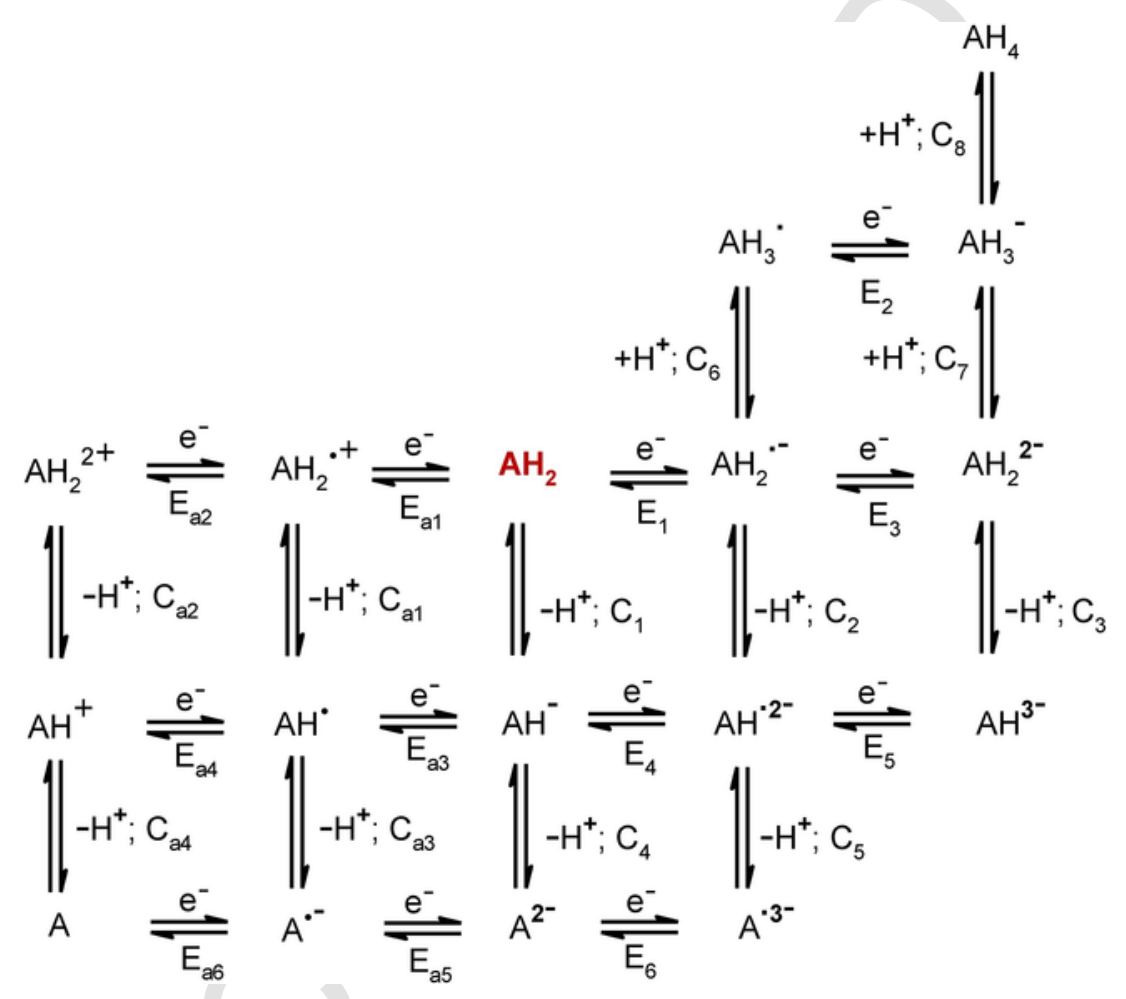

Scheme 2. General electrochemical scheme proposed for ALZ $\left(\mathrm{AH}_{2}\right)$ in non-aqueous solvent in the absence and the presence of proton donor and bases.

This makes the use of alizarin chromophore suitable since it is sensitive to the presence of proton acceptor agents even in non-aqueous solutions [18]. A similar behaviour is observed for ALS [19]. The absorption spectrum of CA in water at different $\mathrm{pHs}(3.0-12.0)$ has also been studied. In the analysed interval of $\mathrm{pH}, \mathrm{CA}$ is found under three different forms, mono $\left(\mathrm{CA}^{-}\right)$, di $\left(\mathrm{CA}^{2-}\right)$ and tri $\left(\mathrm{CA}^{3-}\right)$ anionic forms with the corresponding absorption maxima at $490\left(\mathrm{CA}^{-}\right), 558\left(\mathrm{CA}^{2-}\right)$, 530 and $566 \mathrm{~nm}\left(\mathrm{CA}^{3-}\right)$. In the explored $\mathrm{pH}$ interval, CA passes from the mono-anion at $\mathrm{pH} 3$ till the tri-anion at $\mathrm{pH} 12$ [20]. Solvent effects on the spectra of ALZ and PP dyes are interpreted in terms of intra- and inter-molecular hydrogen-bonding interactions. Less polar non-protic solvents hardly affect the spectrum, whereas red shifts of the absorption maxima are observed in protic solvents. This behaviour is rationalized on the basis of the formation of hydrogen bonds with the solvent [21].

Among the reactions that may experience anthraquinone dyes, the electrochemical ones often offer very broad possibilities of reactivity, parent molecule derivatization or mechanistic analysis. The electron transfer reactions involving quinones and hydroquinones are very important in biological systems and in many areas of chemistry. In this context, electroorganic synthesis can provide an interesting and practical alternative to conventional methods for synthesis. Since toxic 
and hazardous redox reagents are either replaced by electric current (direct electrolysis) or are generated in situ from stable and non-hazardous precursors (indirect electrolysis), electrosynthesis is considered to be a safe and environmentally friendly methodology. A further interesting feature is that electrochemical reactions are feasible under very mild conditions since the reaction rate is determined by the electrode potential, with the possibility of carrying out reactions with high activation energies at low temperatures.

Not many works on the electrochemical behaviour of 9,10-anthraquinone dyes are reported in the literature. The electrochemical studies on these dyes have mainly been performed in aqueous solution. Research on adsorption of anthraquinone dyes on hanging mercury drop electrodes [22], electrochemical degradation of anthraquinone dyes [23], electrochemical incineration of dyes [24], the use of 9,10-anthraquinones as mediators for the indirect cathodic reduction of dyes [25], and the electrochemical analysis of natural solid organic dyes and pigments [26] are some examples.

It is known that the use of organic solvents has several advantages over water in electrochemical studies [27]. Understanding the electrochemical behaviour of the anthraquinone dyes organic molecules in solution of non-aqueous solvents is interesting because it offers the possibility of select the best experimental conditions for transforming the parent molecule by specific synthetic routes, that often are very difficult by traditional thermal routes $[27,28]$. The fact that experimental conditions can substantially affect the course and the products of an electrolysis requires a thorough knowledge of the effects of the changes in the experimental variables (supporting electrolyte, $\mathrm{pH}$, solvent, potential, etc.) on electrode reactions. An understanding of the effects of such variables is absolutely necessary for the design and interpretation of the electrochemical results. During the study of the effects of the changes in the experimental variables on the electrode reactions, we observe a very important and unexpected influence of the supporting electrolyte $\left(\mathrm{NaClO}_{4}\right.$ vs. $\left.\mathrm{R}_{4} \mathrm{~N}^{+} \mathrm{ClO}_{4}{ }^{-}\right)$on the voltammetry behaviour of the dyes. It was therefore of interest to try to explain the role of sodium ion to modify electrochemical behaviour so markedly. It is a known fact that with tetraalkylamonium salts as supporting electrolyte, the reduction of quinones in aprotic solvents take place by two successive one-electron reduction steps generating two separate cathodic waves in which the first step is completely reversible and the second step is quasi-reversible. The first step corresponds to the formation of a semiquinone radical while the second reduction corresponds to the formation of the quinone dianion [29].

The techniques employed in our investigation are cyclic voltammetry $(\mathrm{CV})$ which allows a rapid detection of electrochemical activity of the organic molecule as well as provide a versatile mechanistic approach, and UV-vis spectroscopy.

\section{EXPERIMENTAL}

Solutions preparation, electrochemical experiments and other manipulations were carried out inside a glove-box under dry nitrogen atmosphere. Non-aqueous solvents and inorganic compounds were purified by standard methods [30]. Solvents (acetonitrile (ACN), N,N-dimethylformamide (DMF), N-methylformamide (NMF), formamide (FM), dimethylsulfoxide (DMSO), dimethylacetamide (DMA), pyridine (Py), tetramethylurea (TMU), propylene carbonate (PC), hexamethylphosphoramide (HMPA), methanol $(\mathrm{MeOH})$, ethanol (EtOH), and ethylenediamine (EDA) were dried with freshly activated 4A molecular sieves and stored in the dry glove-box on freshly activated molecular sieve. A LYP-M2 potentiostat, a 3-module LYP sweep generator and a WinPCChrom digital Data Acquisition Module were used. CV experiments were performed in a conventional undivided gas-tight glass cell with dry nitrogen gas inlet and outlet. The work- ing electrode (WE) was a $3 \mathrm{~mm}$ diameter vitreous carbon disk encapsulated in Teflon, the counter-electrode (CE) was a $2 \mathrm{~cm}^{2} \mathrm{Pt}$ foil, and $\mathrm{Ag}^{+}(0.1 \mathrm{M}, \mathrm{ACN}) / \mathrm{Ag}$ was used as reference electrode (to which all reported potentials are referred). Prior to each electrochemical measurement the WE was polished with alumina up to $1 \mu \mathrm{m}$, and then thoroughly ultrasonically rinse. Sodium perchlorate $\left(\mathrm{NaClO}_{4}\right)$ was used as supporting electrolyte unless otherwise stated. The preparation of the basic solutions was performed by adding an exactly known volume of a concentrated solution of known concentration of dry $\mathrm{KOH}$ in absolute ethanol to the solution of the dye in the cell.

The typical employed concentrations of $\mathrm{KOH}$ in the ethanol solutions were 0.1 to $1 \mathrm{M}$ depending on the desired final $\mathrm{KOH}$ concentration. The volumes of the ethanol solutions ranged from 5 to $50 \mu \mathrm{l}$ for a total volume of $2-3 \mathrm{ml}$. The preparation of the TFA solutions was carried out by adding the pure acid to obtain the most concentrated solutions or from solutions suitably diluted in the solvent under study.

All analytical grade dyes were purified by recrystallization and their purity was checked by thin layer chromatography (TLC). For TLC, Silica gel 60 F254 plates from Merck were used and examined under UV light irradiation $(254,365$, and $200-800 \mathrm{~nm})$. UV-vis spectral measurements were made with a Shimadzu-1800 spectrophotometer equipped with a thermostatic cell holder. Teflon-stoppered quartz cells with a 1-cm optical path were used.

For all dyes investigated, peak current intensities for the first electro-reduction process (Icp1) increased linearly with the square root of the potential sweep rate $(v)$ in the range $0.050-0.300 \mathrm{Vs}^{-1}$, unless otherwise specified. The CVs presented in this work are those measured at $v: 0.200 \mathrm{Vs}^{-1}$.

\section{RESULTS AND DISCUSSION}

The investigation was performed on ALZ, PP, QZ, ALS and CA in solution of thirteen polar non-aqueous solvents commonly used for electrochemical studies, without and with H-bond ability, and with different strength as Lewis acids [31], but most experiments were focused on ALZ in DMF solution. The measurements were carried out in the absence and in the presence of added acid (trifluoracetic acid, TFA) or base (KOH). $\mathrm{NaClO}_{4}$ was used as supporting electrolyte, though some experiments were performed with ammonium salts (tetraethylammonium perchlorate, TEAP; tetrabutylammonium perchlorate, TBAP; tetrabutylammonium hexafluorophosphate, TB$\mathrm{NPF}_{6}$ )

\subsection{UV-vis spectrophotometry}

UV-vis spectra give information about the initial structure of the dye (protonated, partially or totally deprotonated species). UV-vis spectra of the dyes were measured in solution of the non-aqueous solvents employed for the electrochemical experiments. Some examples are shown for ALZ in the absence (Fig. 1) and in the presence of added acid (Fig. 2) or base (Fig. 3).

\subsection{Cyclic voltammetry}

\subsubsection{Alizarin}

Cathodic and anodic charge transfer processes are shown in the CVs measured for ALZ in solution. Several aspects are taken into account to rationalize the global electrochemical process and to propose a reaction mechanism for the phenol-quinone dye. First, it must be considered that this molecule possesses two acidic protons, which could be involved in homogeneous equilibrium reactions that could take place in the electrochemical process in the absence of added acid 


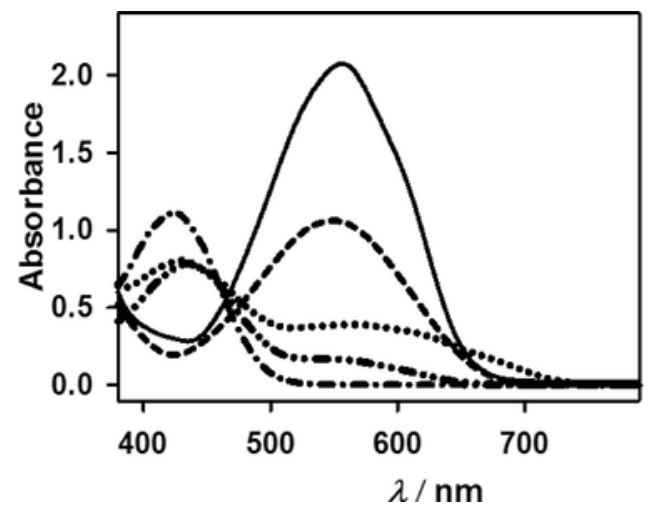

Fig. 1. UV-vis spectra of ALZ in different solvents (ALZ molar concentration). (- - ) FM $\left(1.910^{-4} M\right) ;(---) \operatorname{NMF}\left(1.910^{-4} M\right) ;(\bullet \bullet \bullet) \operatorname{DMF}\left(2.010^{-4} M\right) ;(-\bullet-\bullet)$ $\operatorname{ACN}\left(1.910^{-4} M\right) ;(\bullet-\bullet \bullet-) \operatorname{EtOH}\left(1.610^{-4} M\right)$.

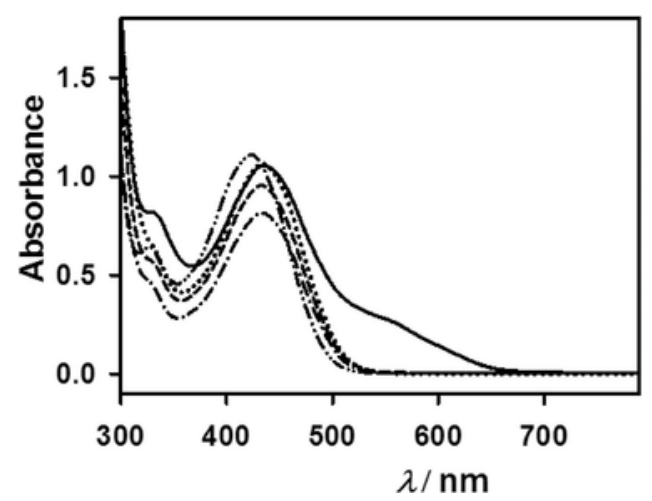

Fig. 2. UV-vis spectra of ALZ (molar concentration) in different solvent solutions with $20 \mathrm{mM}$ TFA added. (- $\mathrm{FM}\left(1.910^{-4} \mathrm{M}\right) ;(---) \mathrm{NMF}\left(1.910^{-4} \mathrm{M}\right) ;(\bullet \bullet \bullet \bullet) \mathrm{DMF}$ $\left(2.010^{-4} \mathrm{M}\right)$; $(-\bullet-\bullet) \mathrm{ACN}\left(1.910^{-4} \mathrm{M}\right) ;(-\bullet \bullet-) \mathrm{EtOH}\left(1.610^{-4} \mathrm{M}\right)$.

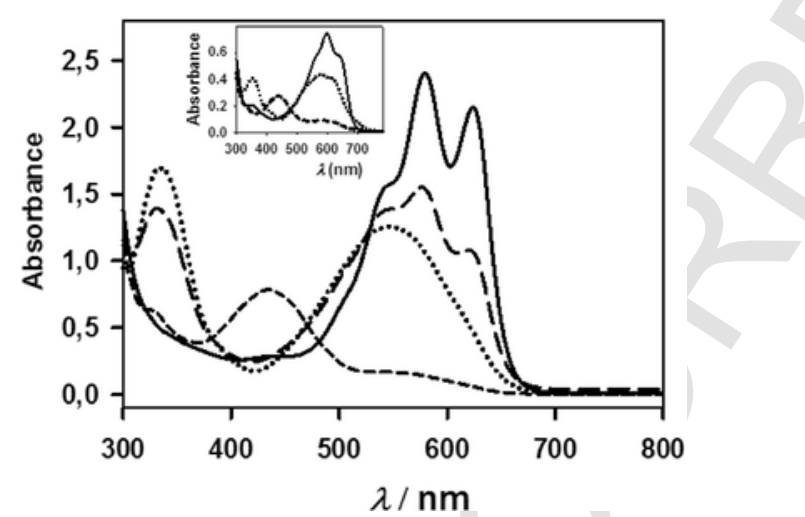

Fig. 3. UV-vis spectra of ALZ $\left(1.610^{-4} \mathrm{M}\right)$ in EtOH (-- ). The same solution with different final concentrations of added $\mathrm{KOH}:(\bullet \bullet \bullet \bullet) 1.5 \mathrm{mM} ;(---) 7.5 \mathrm{mM}$; $(-)$ $30 \mathrm{mM}$. Inset: $0.057 \mathrm{mM} \mathrm{ALZ}$ in DMF solution in absence and in presence of added $\mathrm{KOH}$ in different concentrations: $(---) 0 \mathrm{mM} ;(\bullet \bullet \bullet \bullet) 0.17 \mathrm{mM} ;(-) 0.39 \mathrm{mM}$.

or base. Supporting electrolyte, solvent and added acid or base effects on the electrochemical processes are observed and rationalized.

\subsubsection{Alizarin in DMF solution in the absence of added acid or base}

CVs measured for ALZ ( $\mathbf{A H}_{2}$ for simplicity, two acidic protons) in DMF solution with supporting electrolytes such as tetrabutylam- monium hexafluorophosphate $\left(\mathrm{TBNPF}_{6}\right)$ or ammonium perchlorate salts (TEAP or TBAP) show only two reversible redox couples. Some experiments are shown in Fig. 4a. However, the CVs measured for ALZ in DMF with $\mathrm{NaClO}_{4}$ as supporting electrolyte show three quasireversible charge transfers $\left(c p 1-3_{\mathrm{DMF}}\right.$, Fig. $4 \mathrm{~b}$, full line) at $E c p 1_{\mathrm{DMF}}=-1.19 \mathrm{~V} ; E c p 2_{\mathrm{DMF}}=-1.47 \mathrm{~V}$ and $E c p 3_{\mathrm{DMF}}=-1.91 \mathrm{~V}$ in the initial cathodic sweep and one a quasireversible single peak at $\operatorname{Eap}_{\mathrm{DMF}}=+0.68 \mathrm{~V}$ in the initial anodic scan (Fig. 5, full line and Table 1).

For ALZ as a typical example, it can be suggested that the main processes that occur in solution of non-aqueous solvents are two successive electron transfers generating the corresponding radical anion $\left(\mathbf{A H}_{2}{ }^{-}{ }^{-}\right)$and the dianion $\left(\mathbf{A H}_{2}{ }^{2-}\right)$. This basic scheme may be modified by protonation-deprotonation equilibria and by intermolecular proton transfers which are, therefore, the next reaction steps for the reaction of the electro-generated bases $\mathbf{A H}_{2}{ }^{-{ }^{-}}$and $\mathbf{A} \mathbf{H}_{2}{ }^{2-}$. Thus, the general outline of the Scheme 2 for the electrochemical reactions of ALZ is proposed. The possibility of intramolecular hydrogen exchange does not alter the general scheme, since each species formally maintains its molecular formula.

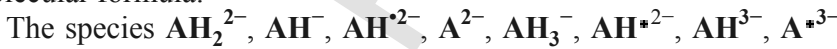
and $\mathbf{A}$ have the formal structures shown in Scheme 3. All structures are resonance hybrids and tautomers; more stable resonance structures are shown.

Since DMF has proton abstracting power [32], the phenolic hydroxyls in $\mathbf{A H}_{2}$ molecule are partially dissociated (see UV-vis spectrum in Fig. 1). In this condition, the species $\mathbf{A} \mathbf{H}_{2}$ and $\mathbf{A} \mathbf{H}^{-}$(equilibrium $\mathbf{C 1}$, Scheme 2) are present in the solution of $\mathbf{A} \mathbf{H}_{\mathbf{2}}$ in DMF. And it is also possible to consider the presence of a small quantity of the $\mathbf{A}^{\mathbf{2}}$ as observed in the UV-vis spectrum (absorption ca. $620 \mathrm{~nm}$ ) (Fig. 1). In this case, the reaction would occur through the reduction of $\mathbf{A H}_{2}$, $\mathbf{A H}^{-}$and $\mathbf{A} \mathbf{H}^{*}{ }^{2-}$, i.e. the contribution of $\mathbf{C 4}$ equilibrium (Scheme 2) is considered negligible. Within Scheme 2, the route chosen by the ALZ-DMF- $\mathrm{NaClO}_{4}$ system is shown in Scheme 4.

Relative intensities of the peaks are dependent on the extension of the previous dissociation equilibrium $\mathbf{C 1}$. The concentration of $\mathbf{A H}^{-}$, which is the origin of the second cathodic wave $\left(c p 2_{\mathrm{DMF}}\right)$, is supplied by the chemical equilibrium $\mathbf{C 1}$ while the concentration of $\mathbf{A H}$ - ${ }^{2-}\left(c p 3_{\mathrm{DMF}}\right)$ is supplied by the charge transfer step E4. Therefore, there should be an effect of the initial concentration of $\mathbf{A H}_{\mathbf{2}}\left(\mathrm{C}_{\mathrm{AH} 2}\right)$ on the current intensity ratios if the Scheme 4 is true. In Fig. 6 is shown the effect of $\mathrm{C}_{\mathrm{AH} 2}$ on the current function $\left(c f=\operatorname{Ip} /\left(v^{1 / 2} C_{A H 2}\right)\right)$. A quantitative analysis of the cathodic waves shows that the value for $c f c p 3_{\mathrm{DMF}} / c f c p 1_{\mathrm{DMF}}$ ratio results 0.60 for $\mathrm{C}_{\mathrm{AH} 2}=20 \mathrm{mM}$, and 1.6 for $\mathrm{C}_{\mathrm{AH} 2}=0.38 \mathrm{mM}$. The greater extent of dissociation at low concentrations, justifies the change in the current intensity ratio. The radical-anion $\mathbf{A H}_{2}{ }^{-}{ }^{-}$formed in $\mathbf{E} 1$ reacts with $\mathbf{A H}_{2}$ to form $\mathbf{A H}_{3}{ }^{*}$ by proton transfer (step $\mathbf{C 1}+\mathbf{C 6}$ ) which is more easily reduced than the neutral organic substrate $\mathbf{A H}_{\mathbf{2}}$ (Scheme 4). As a result, the first and second reductions occur at the same potential $\left(E c p 1_{\mathrm{DMF}}\right)$ and the overall reduction was one step-two electrons $\left(c p 1_{\mathrm{DMF}}\right)$.

A constant potential electrolysis experiment of ALZ in DMF solution performed at the first cathodic peak $(E c p 1=-1.2 \mathrm{~V})$ produced a violet solution. The $\mathrm{CV}$ and $\mathrm{UV}$-vis spectrum of this violet solution are similar to those measured for ALZ in presence of the added base (Figs. 3 and 5). An absorption band at $550 \mathrm{~nm}$ is shown in the UV-vis spectrum of the violet solution. This absorption maximum is assigned to the $\mathbf{A H}^{-}$specie [12-14]. This experiment confirms the incorporation of the second step $(\mathbf{C 1}+\mathbf{C 6})$ in Scheme 4.

The presence of the species $\mathbf{A H}_{\mathbf{2}}$ and $\mathbf{A} \mathbf{H}^{-}$in the initial solution is supported by the UV-Vis spectrum. UV-vis spectra of ALZ in solution of DMF and in the different non-aqueous solvents used in this work shown in Fig. 1 (DMF: dotted line) present two maximum at 

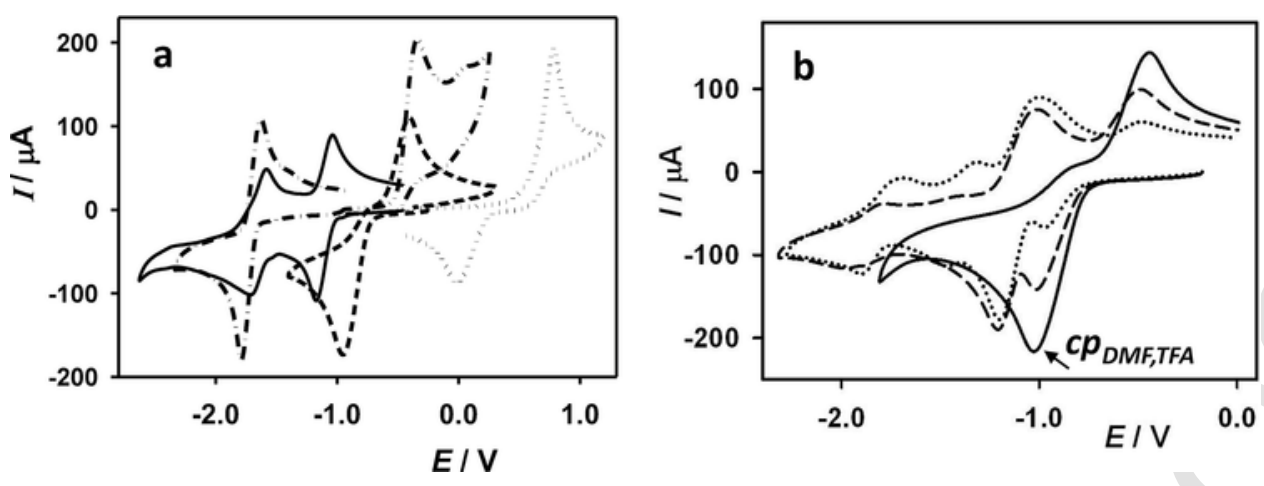

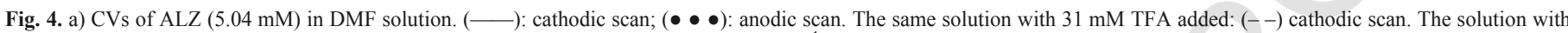

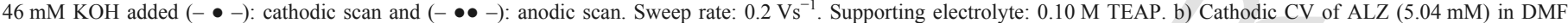
solution with TFA added in different final concentrations: $(\bullet \bullet \bullet \bullet) 1.8 \mathrm{mM} ;(---) 3.9 \mathrm{mM}$; $(-) 12 \mathrm{mM} . v: 0.200 \mathrm{Vs}^{-1}$; supporting electrolyte: $0.10 \mathrm{M} \mathrm{NaClO}_{4}$

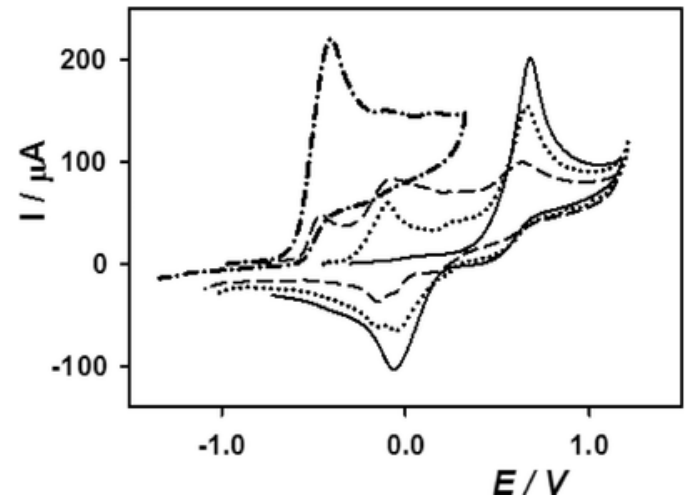

Fig. 5. Anodic CV of ALZ (5.04 mM) in DMF solution (-). Same solution with $\mathrm{KOH}$ added in different final concentrations: $(\bullet \bullet \bullet \bullet) 2.1 \mathrm{mM} ;(---) 5.2 \mathrm{mM} ;(-\bullet-$ •) $56 \mathrm{mM}$. $v$ : $0.200 \mathrm{Vs}^{-1}$; supporting electrolyte: $0.10 \mathrm{M} \mathrm{NaClO}_{4}$. $\mathrm{KOH}$ was added from a solution of $\mathrm{KOH}$ in ethanol containing $0.051 \mathrm{~g}$ of anhydrous $\mathrm{KOH}$ per $\mathrm{g}$ of solution.

429 and $565 \mathrm{~nm}$, corresponding to the species $\mathbf{A} \mathbf{H}_{2}$ and $\mathbf{A H}{ }^{-}$, respectively.

The global reaction (GR) corresponding to Scheme 4 is: $\mathrm{AH}_{2}+2 \mathrm{e}^{-} \leftrightarrows \mathrm{AH}_{2}{ }^{2-}$

The voltammograms of the dyes in organic solvent solutions measured using ammonium salts show only two reversible redox couples, similar to the typical response of quinones (e.g. 9,10- anthraquinone) in non-aqueous solvent solution in the absence of added acid or base. Instead, more electro-reduction peaks are detected in voltammograms measured using $\mathrm{NaClO}_{4}$ as supporting electrolyte. The results with ammonium salts has led to an erroneous conclusion in some published works that the electro-reduction of these dyes only proceeds through the formation of a radical anion and dianion. When sodium or lithium salts are employed, the occurrence of complexation reactions or ion pair formation $[33,34]$ between the negatively charged species, such as $\mathbf{A H}{ }^{{ }^{2-}}$ or $\mathbf{A H}_{2}{ }^{2-}$, with $\mathrm{Na}^{+}$or $\mathrm{Li}^{+}$cations produce cathodic shifts in some electro-reduction peak potentials, and a greater number of reduction waves can be detected in the CVs. This behaviour reflects stabilization of the negatively charged forms in the presence of metal alkaline ions. Tetraalkylammonium ions in solution may cause no chemical interactions through coordination or hydrogen bonding since the coordination numbers of the central elements in the species (ions) are fully satisfied, apart from their excellent three-dimensional symmetries. The peak potentials of the first couple do not change significantly when using sodium or ammonium salts showing that the complexation reactions are negligible for the monoanionic species [35].

\subsubsection{Effect of added proton source}

The addition of anhydrous TFA drastically changes the voltammetric behaviour of ALZ in DMF solution (Fig. 7 and Table 1). The original cathodic peaks ( $c p 1-3_{\mathrm{DMF}}$ ) disappear, and are replaced by a quasireversible peak at $E c p_{\text {DMF,TFA }}=-0.99 \mathrm{~V}$ in the initial cathodic sweep (e.g. $\mathrm{R}_{\mathrm{TFA}}=[\mathrm{TFA}] /[\mathrm{ALZ}] \approx 2.4$, see Fig. 7). The quasireversible original anodic peak practically does not change when TFA is added to the electrolytic medium (not shown). The main reduction reaction in the presence of the added acid is the generation of the tetrahydroxy $\left(\mathbf{A H}_{\mathbf{4}}\right)$ compound (Scheme 5) [29,36,37].

Results shown in Tables 1 and 2 (in Supplementary Material) are those measured with an excess of added TFA $\left(\mathrm{R}_{\mathrm{AH}}=[\mathrm{TFA}] /[\right.$ $\mathrm{ALZ}] \approx 5$ ). The CVs were not modified for further addition of the proton donor. The most probable way in the presence of excess added acid (do not exist $\mathbf{A} \mathbf{H}^{-}$and $\mathbf{A}^{2-}$ ) is the well-known ECEC mechanism with E2 $<$ E1 [38] (see Scheme 2, E1-C6-E2-C8), which is also proposed for the electro-reduction of ALZ in ACN solution in the presence of acid [39]. This sequence of the reactions is described as two rounds of electron-transfer coupled with proton acceptance (chemical reaction), that is ECEC (or EHEH) mechanism. Previous protonation of ALZ is discarded due to the low basicity of the carbonylic and phenolic oxygens in the non-aqueous solvents and because the quasireversible original anodic peak does not change when TFA is added to the electrolytic medium (see above in this section).

\subsubsection{Effect of the added base}

The addition of $\mathrm{KOH}$ in increasing $\mathrm{R}_{\mathrm{KOH}}=[\mathrm{KOH}] /[\mathrm{ALZ}]$ molar ratio to a solution of ALZ in DMF results in a successive disappearance of $c p 1_{\mathrm{DMF}}$ and $c p 2_{\mathrm{DMF}}$ (Fig. $4 \mathrm{~b}$ ). At the same time, it appears and increases in intensity a new reversible cathodic peak at $E c p_{\mathrm{DMF}, \mathrm{KOH}}=-1.95 \mathrm{~V}$, very close to $c p 3_{\mathrm{DMF}}$ measured in absence of the added base. For intermediate $\mathrm{R}_{\mathrm{KOH}}$ molar ratio values (e.g. $\mathrm{R}_{\mathrm{KOH}} \approx 1$ ) the $\mathrm{CV}$ shows two cathodic peaks (Fig. 4b, dashed line) and for higher $\mathrm{R}_{\mathrm{KOH}}$ ratios $\left(\right.$ e.g. $\left.\mathrm{R}_{\mathrm{KOH}}>2\right)$ only the new reversible redox couple is observed (Fig. $4 \mathrm{~b}, \mathrm{R}_{\mathrm{KOH}} \approx 11$, dotted-dashed line). To rationalize the $\mathrm{CV}$ changes in the presence of added base the reactions C4, E4 ( $E c p 2_{\mathrm{DMF}}$ : $\left.-1.44 \mathrm{~V}\right), \mathbf{C 5}, \mathbf{E 6}\left(E c p_{\mathrm{DMF}, \mathrm{KOH}}:-1.95 \mathrm{~V}\right)$ included in the general reaction scheme (Scheme 2) must be considered. The anion $\mathbf{A}^{\mathbf{2 -}}$ (C4 in Scheme 2) is the predominant species for high $\mathrm{R}_{\mathrm{KOH}}$ values $\left(\mathrm{R}_{\mathrm{KOH}}>2\right)$ and the only possible reaction is its reversible electro-reduction E6. The non-availability of protons makes the reaction stops at this stage. The electro-reduction of the radical-anion $\mathbf{A}^{\mathbf{*}^{3-}}$ (formed in E6, Scheme 2) is less probable and possibly occurs outside the usable potential range of the solvent. The current function for the peak at $E c p_{\mathrm{DMF}, \mathrm{KOH}}=-1.95 \mathrm{~V}$ (Fig. 4b) is $64 \mathrm{~A} \mathrm{~V}^{-1 / 2}$ $\mathrm{s}^{1 / 2} \mathrm{M}^{-1} 10^{-3}$ (Table 1 ). This value is approximately the half value 
Table 1

$\mathrm{CV}$ results for the electrochemical processes of alizarin (ALZ). $\mathrm{ALZ}$ conc. $5.00 \mathrm{mM}$; potential sweep rate: $0.200 \mathrm{Vs}^{-1}$; supporting electrolyte: $0.10 \mathrm{M} \mathrm{NaClO}$.

\begin{tabular}{|c|c|c|c|c|c|c|c|}
\hline Solvent & $\begin{array}{l}\text { Added acid } \\
\text { or base }^{\mathrm{a}}\end{array}$ & $\begin{array}{l}\text { Number of processes of } \\
\text { electro- reduction }\end{array}$ & $E c p_{\text {solv }} / \mathrm{V}$ & $\begin{array}{l}\text { Current function/A } \\
\mathrm{V}^{-1 / 2} \mathrm{~s}^{1 / 2} \mathrm{M}^{-1} 10^{-3}\end{array}$ & $\begin{array}{l}\text { Number of processes of } \\
\text { electro- oxidation }\end{array}$ & $\operatorname{Eap}_{\text {solv }} \sim \mathrm{N}$ & $\begin{array}{l}\text { Current function/A } \\
\mathrm{V}^{-1 / 2} \mathrm{~s}^{1 / 2} \mathrm{M}^{-1} 10^{-3}\end{array}$ \\
\hline \multirow[t]{5}{*}{$\mathrm{ACN}^{\mathrm{b}}$} & --- & 3 & -0.96 & 71 & 1 & +1.14 & 177 \\
\hline & & & -1.27 & 14 & & & \\
\hline & & & -1.48 & 8 & & & \\
\hline & Acid & 1 & -0.55 & 152 & 1 & +1.15 & 183 \\
\hline & Base & 1 & -1.56 & $\begin{array}{l}\text { Very low (almost } \\
\text { insoluble) }\end{array}$ & --- & & \\
\hline \multirow[t]{6}{*}{ DMA } & --- & 3 & -1.21 & 44 & 1 & +0.64 & 82 \\
\hline & & & -1.52 & 13 & & & \\
\hline & & & -1.98 & 25 & & & \\
\hline & Acid & 1 & -1.08 & 72 & 1 & +0.62 & 88 \\
\hline & Base & 1 & 2.00 & 56 & 3 & -0.35 & 84 \\
\hline & & & & & & $\begin{array}{l}-0.06 \\
+0.23\end{array}$ & \\
\hline \multirow[t]{6}{*}{ HMPA } & --- & 3 & -1.36 & 20 & 1 & $+0.13(\mathrm{sh})$ & 9 \\
\hline & & & -1.78 & 9 & & & \\
\hline & & & -2.44 & 12 & & & \\
\hline & Acid & 1 & -1.32 & 43 & & & \\
\hline & Base & & $-2.12^{\mathrm{c}}$ & 21 & 2 & $-0.57^{\mathrm{d}}$ & 11 \\
\hline & & & & & & $-0.13^{\mathrm{d}}$ & 12 \\
\hline \multirow[t]{7}{*}{$\mathrm{MeOH}$} & --- & 3 & -1.02 & 63 & 1 & +0.80 & 123 \\
\hline & & & -1.25 & 55 & & & \\
\hline & & & -1.69 & 9 & & & \\
\hline & Acid & 2 & -0.74 & 131 & 1 & +0.84 & 135 \\
\hline & & & -1.10 & 36 & & & \\
\hline & Base & 1 & -1.23 & 78 & 2 & -0.20 & 47 \\
\hline & & & & & & +0.035 & 118 \\
\hline \multirow[t]{4}{*}{$\mathrm{EtOH}$} & --- & 2 & -1.12 & 40 & 1 & +0.73 & 75 \\
\hline & & & -1.55 & 32 & & & \\
\hline & Acid & 1 & -0.76 & 85 & 1 & +0.75 & 78 \\
\hline & Base & 1 & -1.68 & 54 & 2 & +0.02 & 93 \\
\hline \multirow[t]{5}{*}{ Py } & --- & 3 & -1.20 & 37 & 1 & +0.34 & 142 \\
\hline & & & -1.71 & 33 & & & \\
\hline & & & -2.61 & 73 & M & & \\
\hline & Acid & 1 & -1.10 & 100 & 1 & +0.40 & 99 \\
\hline & Base & 1 & -1.66 & 20 & 1 & +0.33 & 14 \\
\hline \multirow[t]{5}{*}{ DMF } & --- & 3 & -1.19 & 57 & 1 & +0.68 & 105 \\
\hline & & & -1.47 & 24 & & & \\
\hline & & & -1.91 & 35 & & & \\
\hline & Acid & 1 & -0.99 & 91 & 1 & +0.66 & 101 \\
\hline & Base & 1 & -1.95 & 64 & 1 & -0.40 & 94 \\
\hline \multirow[t]{6}{*}{ DMSO } & --- & 3 & -1.19 & 31 & 1 & +0.66 & 52 \\
\hline & & & -1.44 & 9 & & & \\
\hline & & & -2.01 & 17 & & & \\
\hline & Acid & 1 & -0.91 & 51 & 1 & +0.66 & 54 \\
\hline & Base & 1 & $-2.08^{\mathrm{e}}$ & 50 & 1 & $-0.36^{\mathrm{f}}$ & 76 \\
\hline & & & & & & $\begin{array}{l}(-0.43,-0.13 \text { and } \\
+0.28)^{\mathrm{f}}\end{array}$ & \\
\hline \multirow[t]{4}{*}{ FM } & --- & 2 & -1.07 & 28 & 1 & +0.026 & 27 \\
\hline & & & -2.54 & 57 & & & \\
\hline & Acid & 1 & -1.02 & 49 & 1 & +0.089 & 49 \\
\hline & Base & 1 & -1.53 & 9 & 1 & -0.051 & 11 \\
\hline \multirow[t]{4}{*}{ NMF } & --- & 2 & -1.15 & - & 1 & +0.10 & 45 \\
\hline & & & 1.32 & & & & \\
\hline & Acid & 1 & -1.15 & 62 & 1 & +0.59 & 54 \\
\hline & Base & 1 & -1.69 & 40 & 1 & -0.30 & 63 \\
\hline \multirow[t]{5}{*}{ NMA } & --- & 2 & -1.19 & 18 & 2 & +0.09 & 4 \\
\hline & & & -1.44 & 7 & & +0.63 & 22 \\
\hline & Acid & 1 & -0.93 & 34 & 1 & +0.61 & 32 \\
\hline & Base & 1 & -1.74 & 23 & 2 & -0.28 & 28 \\
\hline & & & & & & -0.09 & 6 \\
\hline $\mathrm{PC}$ & --- & 3 & -1.13 & 20 & 1 & +1.11 & 44 \\
\hline & & & -1.41 & 7 & & & \\
\hline & & & -1.74 & 9 & & & \\
\hline & Acid & 1 & -0.85 & 48 & 1 & +1.11 & 53 \\
\hline & Base & Insoluble & & & Insoluble & & \\
\hline TMU & --- & 1 & -1.23 & 62 & 1 & +0.68 & 70 \\
\hline & Acid & 1 & -1.06 & 56 & 1 & +0.65 & 66 \\
\hline & Base & 1 & -1.74 & 31 & 2 & -0.39 & 16 \\
\hline & & & & & & +0.10 & 27 \\
\hline EDA & --- & 1 & -1.53 & 37 & 1 & -0.068 & 65 \\
\hline & Acid & 1 & -1.43 & 51 & 1 & -0.14 & 71 \\
\hline
\end{tabular}


Table 1 (Continued)

\begin{tabular}{|c|c|c|c|c|c|c|c|}
\hline Solvent & $\begin{array}{l}\text { Added acid } \\
\text { or base }^{\mathrm{a}}\end{array}$ & $\begin{array}{l}\text { Number of processes of } \\
\text { electro- reduction }\end{array}$ & $E c p_{\text {solv }} / \mathrm{V}$ & $\begin{array}{l}\text { Current function/A } \\
\mathrm{V}^{-1 / 2} \mathrm{~s}^{1 / 2} \mathrm{M}^{-1} 10^{-3}\end{array}$ & $\begin{array}{l}\text { Number of processes of } \\
\text { electro- oxidation }\end{array}$ & $\operatorname{Eap}_{\text {solv }} / \mathrm{V}$ & $\begin{array}{l}\text { Current function/A } \\
\mathrm{V}^{-1 / 2} \mathrm{~s}^{1 / 2} \mathrm{M}^{-1} 10^{-3}\end{array}$ \\
\hline & Base & 1 & -1.94 & 47 & 1 & -0.28 & 62 \\
\hline
\end{tabular}

a The results in the presence of added acid or base were measured on the voltamperograms recorded with an excess of acid (Racid = [TFA]/[ALZ] ca. 5) or base. The base

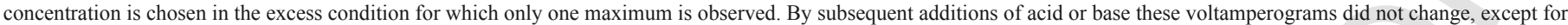
some examples (shall be indicated at the foot of the table) for which special base concentrations are used to observe the intermediate peaks.

b $2.58 \mathrm{mM}$ Alizarin.

c For $75 \mathrm{mM} \mathrm{KOH}$.

${ }^{\text {d For }} 21 \mathrm{mM} \mathrm{KOH}$.

e For $40 \mathrm{mM} \mathrm{KOH}$.

${ }^{f}$ For $10 \mathrm{mM} \mathrm{KOH}$<smiles>[O-]c1c2cc(O)ccc2c(O)c2c([O-])cccc12</smiles>

$\mathrm{AH}_{2}{ }^{2-}$<smiles>O=C1c2ccccc2C(=O)c2c1ccc([O-])c2[O-]</smiles><smiles>[O-]c1ccc2c([O-])c3ccccc3c([O-])c2c1O</smiles>

$\mathrm{AH}^{3-}$<smiles>Cc1ccc(O)c([O-])c1C</smiles><smiles>O=C1c2ccccc2C(=O)c2c1ccc([O-])c2O</smiles><smiles>O=C1c2ccccc2C([O-])c2c1ccc(O)c2O</smiles><smiles>O=C1c2ccccc2C([O-])c2c1ccc([O-])c2[O-]</smiles><smiles>O=c1ccc2c(=O)c3ccccc3c(=O)c=2c1=O</smiles>

A

Scheme 3. Formal structures for the species in Scheme 2.

than that which is measured in absence of the added base (Table 1, three cathodic peaks $(c p 1-3): 57+24+35=116 \mathrm{~A} \mathrm{~V}^{-1 / 2} \mathrm{~s}^{1 / 2} \mathrm{M}^{-1}$ $10^{-3}$, two electrons). Therefore, ALZ exchanges one electron per molecule for $\mathrm{R}_{\mathrm{KOH}}>2$.

Bechtold et al. [25] postulate the direct electro-reduction of the neutral species $\left(\mathbf{A H}_{2}\right.$ : several hydroxy-9,10-anthraquinones in ref. [25]) in aqueous basic medium even with a high molar ratio $[\mathrm{NaOH}] /[$ dye] $\approx 200$. The voltammetric and spectrophotometric results obtained in our work invalidate the Bechtold proposed mechanism.

\subsubsection{Alizarin in other solvents}

The electrochemical behaviour of ALZ in solution of solvents other than DMF (in the absence or in the presence of added acid or base) presents some differences and some similarities with the behav- iour in DMF that depend on the solvent. The CVs show a variety of responses for the dye in solution of the different solvents. Some results are shown in Fig. 8 (ACN), and in the Supplementary Material in Figs. 1S (TMU), 2S (FM), 3S (HMPA) and 4S (NMF) and in Table 1, in the absence and in the presence of added acid or base.

\subsection{In the absence of added acid or base}

The number of electro-reduction processes detected in the first cathodic scan varies from three to one (Table 1; 3 processes for ACN, DMA, HMPA, MeOH, Py, DMF, DMSO, and PC; 2 processes for EtOH, FM, NMF, and NMA; 1 process for TMU and EDA) in the absence of added base or acid. The peak potentials and relative current intensities are significantly different from those measured in DMF solution (Table 1). For example, for ALZ in ACN solution 
E1

$(\mathrm{C} 1+\mathrm{C} 6)$

E2

C7

C1

E4

$(\mathrm{C} 1+\mathrm{C} 2)$

E3

E5

$(\mathrm{C} 1+\mathrm{C} 3)$
$\mathrm{AH}_{2}+\mathbf{e}^{-}$

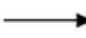

$\mathrm{AH}_{2}{ }^{--}+\mathrm{AH}_{2}$
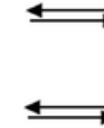

$\mathbf{A H}^{-}+\mathrm{e}^{-}$

$\mathrm{AH}^{\cdot 2-}+\mathbf{A H}_{2}$

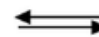

$\mathrm{AH}_{2}{ }^{--}$

Ecp1DMF: $-1.19 \mathrm{~V}$

$\mathrm{H}^{-}+\mathrm{AH}_{3}{ }^{\circ}$

$\mathrm{AH}_{3}$

Ecp1DMF: $-1.19 \mathrm{~V}$

$\mathrm{H}_{2}{ }^{2-}+\mathbf{H}^{+}$

$\mathbf{H}^{-}+\mathbf{H}^{+}$

$\mathbf{H}^{-2-}$

Ecp2DMF: $-1.47 \mathrm{~V}$

$\mathrm{AH}_{2}{ }^{--}+\mathrm{AH}^{-}$

$\mathrm{AH}_{2}{ }^{2-} \quad$ Ecp2 2 DMF: $-1.47 \mathrm{~V}$

$\mathrm{AH}^{3-}$

Ecp3 DMF: $-1.91 \mathrm{~V}$

Scheme 4. Proposed possible route for the electro-reduction of ALZ in DMF in the absence of added base or acid.

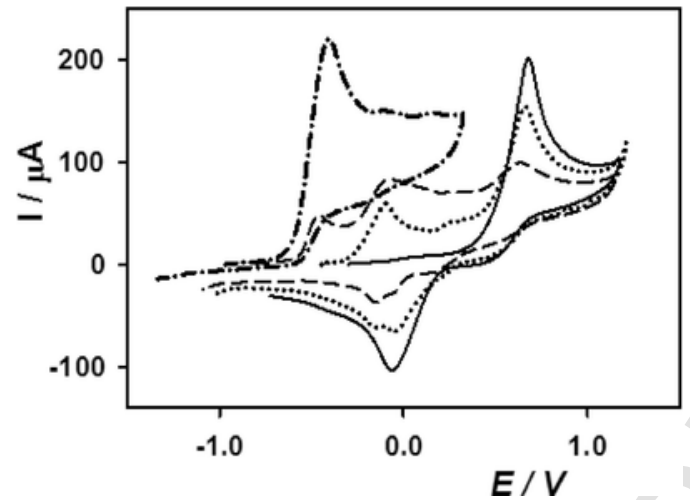

Fig. 6. Cathodic CVs for ALZ in different concentrationes in DMF solution. ( - ): $0.38 \mathrm{mM}$; (- - ) : $20 \mathrm{mM}$. $v$ : $0.200 \mathrm{Vs}^{-1}$; supporting electrolyte: $0.10 \mathrm{M} \mathrm{NaClO}_{4}$. The $\mathrm{CVs}$ are corrected for base line.

(Fig. 8), the cathodic peak at less cathodic potential $\left(c p 1_{\mathrm{ACN}}\right.$, $\left.E c p 1_{\mathrm{ACN}}=-0.96 \mathrm{~V}, c f c p 1_{\mathrm{ACN}}=71 \mathrm{~A} \mathrm{~V}^{-1 / 2} \mathrm{~s}^{1 / 2} \mathrm{M}^{-1} 10^{-3}\right)$ is proportionally much more intense than the others $\left(E c p 2_{\mathrm{ACN}}=-1.27\right.$ and $E c p 3_{\mathrm{ACN}}=-1.48 \mathrm{~V} ; c f c p 2_{\mathrm{ACN}}=14$ and $c f c p 3_{\mathrm{ACN}}=8 \mathrm{~A} \mathrm{~V}^{-1 / 2} \mathrm{~s}^{1 / 2} \mathrm{M}^{-1}$ $10^{-3}$, respectively), that is to say $c f c p 1_{\mathrm{ACN}} / c f c p 2_{\mathrm{ACN}} \approx 5.1$ and $c f c p 1_{\mathrm{ACN}} / c f c p 3_{\mathrm{ACN}} \approx 8.9$ in $\mathrm{ACN}$, while $c f c p 1_{\mathrm{DMF}} / c f c p 2 \mathrm{DMF} \approx 2.4$ and $c f c p 1_{\mathrm{DMF}} / c f c p 3_{\mathrm{DMF}} \approx 1.6$ in DMF solution. This behaviour could be explained as the result of the decrease of the first dissociation constant of ALZ in solution of ACN compared with DMF (step C1, Scheme 2), so the predominant species in ACN is the neutral molecule $\left(\mathbf{A H}_{2}\right)$. This statement is supported by the spectrophotometric UV- vis results and by $\mathrm{pKa}$ data for phenols in solution of organic solvents published in literature [40]. UV-vis spectrum of ALZ in ACN solution presents an absorption band with a maximum at $\lambda_{\max }=424 \mathrm{~nm}$ (Fig. 1) corresponding to $\mathbf{A H}_{\mathbf{2}}$ neutral specie. Therefore, in this solvent, the main route is determined for the steps E1,

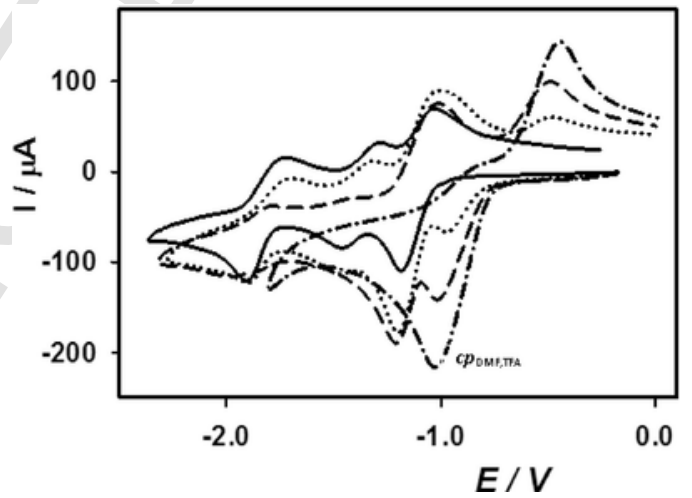

Fig. 7. Cathodic CV of ALZ (5.04 mM) in DMF solution (-). Same solution with TFA added in different final concentrations: $(\bullet \bullet \bullet \bullet) 1.8 \mathrm{mM} ;(---) 3.9 \mathrm{mM}$; $(-\bullet-$ •) $12 \mathrm{mM}$. $v$ : $0.200 \mathrm{Vs}^{-1}$; supporting electrolyte: $0.10 \mathrm{M} \mathrm{NaClO}_{4}$.

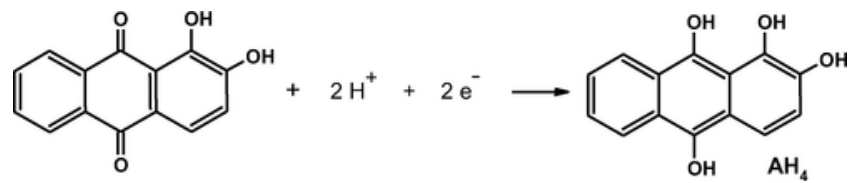

Scheme 5. Equation for the main reaction of electro-reduction of ALZ in acid medium.

$(\mathbf{C 1}+\mathbf{C 6}), \mathbf{E 2}, \mathbf{C} 7$ and $\mathbf{C 1}$ (see Scheme 2). To facilitate the reading these steps are shown in Scheme 6.

The subsequent electro-reduction of $\mathbf{A H}^{-}\left(c p 2_{\mathrm{ACN}}\right)$ depends on the concentration of this anion provided by the equilibrium $\mathbf{C 1}$ practically insignificant in ACN solvent (Fig. 1). The formation of $\mathbf{A H}_{\mathbf{4}}$, that provides a small concentration of the $\mathbf{A \mathbf { H } ^ { - }}$ anion (which is responsible of the small more cathodic peaks $c p 2_{\mathrm{ACN}}$ at $-1.27 \mathrm{~V}$ and $c p 3_{\mathrm{ACN}}$ at $-1.48 \mathrm{~V}$ (Table 1$)$, could be considered as a substitute reaction: $(\mathrm{Cl}+\mathrm{C8}) \mathrm{AH}_{3}{ }^{-}+\mathrm{AH}_{2} \rightarrow \mathrm{AH}_{4}+\mathrm{AH}^{-}$. 


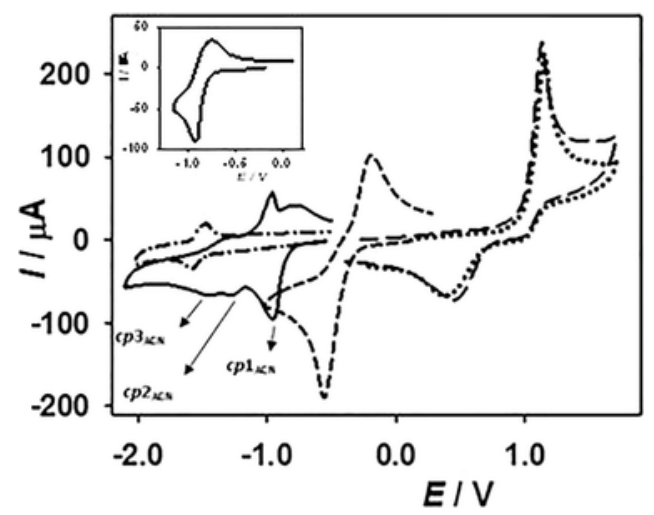

Fig. 8. CVs of ALZ $(2.58 \mathrm{mM})$ in ACN solution. (- - cathodic scan; $(---)$ anodic scan. The same solution with added $7.3 \mathrm{mM}$ TFA: $(---)$ cathodic scan; $(\bullet \bullet \bullet \bullet)$ anodic scan. The same solution with $3.6 \mathrm{mM} \mathrm{KOH}$ added: $(-\bullet-\bullet)$ cathodic scan. $v$ : $0.200 \mathrm{Vs}^{-1}$; supporting electrolyte: $0.10 \mathrm{M} \mathrm{NaClO}_{4}$. The inset shows a CV for ALZ in $\mathrm{ACN}$, including only the first couple.

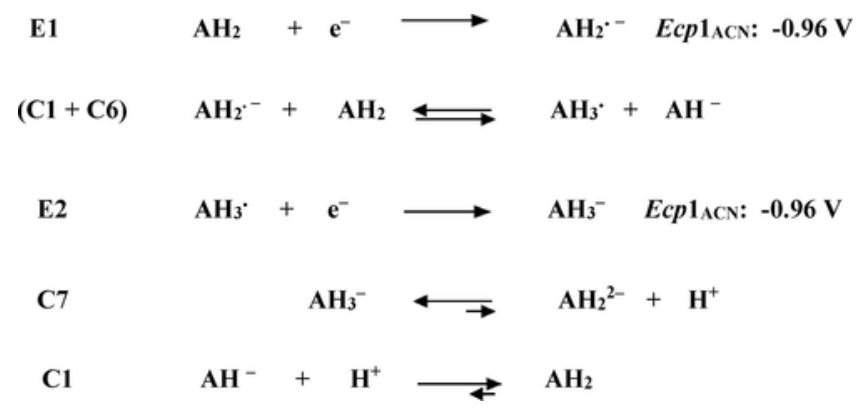

Scheme 6. Mechanism of electro-reduction of ALZ in ACN solution in the absence of added acid or base.

Other fact to be considered to rationalize the CVs of ALZ is the possible precipitation of the sodium salts of the negatively charged species in ACN and other solvents (Tables 1 and 2 in Supplementary Material). If this phenomenon were important, these salts would precipitate in the absence or presence of added base and this is not observed in Fig. 8. However, the precipitation is not completely discarded. For example, in a sweep potential including only the first cathodic peak of $\mathrm{ALZ} / \mathrm{ACN} / \mathrm{NaClO}_{4}$ a decrease of the current intensity for the corresponding anodic peak is observed (see inset in Fig. 8). The precipitation could explain this behaviour. By contrast, in DMSO/Na$\mathrm{ClO}_{4}$ system, PP dye shows (Fig. 10S, full-line) a behaviour similar to that observed for $\mathrm{ALZ}$ in $\mathrm{ACN} / \mathrm{NaClO}_{4}$. In DMSO solvent in the absence or the presence of added base, precipitation does not occur (see Table 2 and Fig. 10S in Supplementary Material). The precipitation cannot describe this behaviour.

The evidence of the $\mathrm{Na}^{+}$effect is on the shifts of the peak potentials. The interaction between opposite charged species is stronger in ACN than in DMF solvent. Then, the shifts of the cathodic peaks to less cathodic potentials are larger for ACN. Both solvents have similar acceptor numbers $\left(\mathrm{AN}_{\mathrm{ACN}}: 18.9 ; \mathrm{AN}_{\mathrm{DMF}}: 16.0\right)$ but the donor number for DMF is higher than for $\mathrm{ACN}\left(\mathrm{DN}_{\mathrm{ACN}}: 14 ; \mathrm{DN}_{\mathrm{DMF}}: 26\right)$, then the weaker interaction of $\mathrm{Na}^{+}$with ACN than with DMF favours the interaction of $\mathrm{Na}^{+}$with the opposite charge species.

The CV behaviour of ALZ in DMSO, DMA, HMPA and PC solution is essentially the same one that was measured in DMF solution.

Only the two cathodic peaks at less cathodic potentials $\left(E c p 1_{\mathrm{NMA}}\right.$ : -1.19 and $\left.E c p 2_{\mathrm{NMA}}:-1.44 \mathrm{~V}\right)$ are present in the $\mathrm{CV}$ of electro-reduction of ALZ in NMA solution (Table 1). Probably a similar rationalization to the mentioned above for ACN solvent may be given.
$\mathrm{CV}$ for ALZ in FM solution (Fig. 2S in Supplementary Material) shows two well separated peaks $\left(E c p 1_{\mathrm{FM}}=-1.07\right.$ (reversible) and $E c p 2_{\mathrm{FM}}=-2.54 \mathrm{~V}$ (irreversible)). The first electro-reduction step is somewhat anodically shifted by $0.12 \mathrm{~V}$ respect to DMF $\left(E c p 1_{\mathrm{DMF}}=-1.19 \mathrm{~V}\right)$. The main specie of ALZ in FM solution is $\mathbf{A H}^{-}$ as it is shown in the UV-vis spectrum $\left(\lambda_{\max } 556 \mathrm{~nm}\right.$, Fig. 1). The current function value for the $c p 1_{\mathrm{FM}}\left(c f c p 1_{\mathrm{FM}}=28 \mathrm{~A} \mathrm{~V}^{-1 / 2} \mathrm{~s}^{1 / 2} \mathrm{M}^{-1}\right.$ $10^{-3}$ ) corresponds to the transference of one electron if it is compared with the value measured in DMF solution (two electrons: $57+24+35=116 \mathrm{~A} \mathrm{~V}^{-1 / 2} \mathrm{~s}^{1 / 2} \mathrm{M}^{-1} 10^{-3}$ or 58 if it is corrected by the different viscosity of the solvents, $\eta_{\mathrm{DMF}}, 25^{\circ} \mathrm{C}=0.80 \mathrm{cP}$ and $\eta_{\mathrm{FM}}=3.30 \mathrm{cP}[41]$. The probable reaction scheme involves the reactions C1, E4 $\left(E c p 1_{\mathrm{FM}}:-1.07 \mathrm{~V}\right)$ and $\mathbf{C 2}$ (see Scheme 2). The specie $\mathbf{A H}^{\bullet^{2-}}$ formed by $\mathbf{E 4}$ is irreversibly electro-reduced at $-2.54 \mathrm{~V}$ (Fig. $2 \mathrm{~S}$ in Supplementary Material and Table 1). In the second electrochemical step the radical dianion, produced in the first step (E4) and also in $\mathbf{C 2}$, is irreversibly reduced to the trianion. The irreversibility is explained by assuming a fast irreversible protonation of the trianion.

It is known that FM has a large dielectric constant (109.5 [41]), a considerably high Gutmann acceptor number $(A N=40)$, a quantitative measure of Lewis acidity of the solvents, and is a solvent with ability to form hydrogen bonding [42]. These characteristic properties of the solvent must produce a high stabilization of the anionic specie $\mathbf{A H}^{*}$ ${ }^{2-}$ which, together with $\mathbf{C 2}$, causes the charge transfer process $(\mathbf{E 4})$ at less cathodic potential than in DMF (Table 1), and also could explain the high cathodic potential for the electro-reduction of $\mathbf{A H}^{\mathbf{*}^{2-}}$ in FM.

For ALZ in NMF solution, the CV shows two very close cathodic peaks at $E c p 1_{\mathrm{NMF}}=-1.15$ (shoulder) and $E c p 2_{\mathrm{NMF}}=-1.32 \mathrm{~V}$ (Fig. $4 \mathrm{~S}$ in Supplementary Material and Table 1) and, a single absorption band at $549 \mathrm{~nm}$ is shown in the UV-vis spectrum (Fig. 1) indicating that the dye is completely mono-dissociated in this solvent, being $\mathbf{A H}^{-}$ the electroactive specie, as in FM. NMF has a lower acceptor number $(A N=32)[42]$ and a lower ability to form hydrogen bonding than FM, but its dielectric constant is very high (182.4). Therefore, the CV of ALZ in NMF solution should present mainly the electro-reduction of this specie as the first electro-reduction step as it is shown in Fig. 4S in Supplementary Material, and the redox mechanism is the same as in FM.

\subsection{In the presence of TFA}

ALZ in the solution of the solvents other than DMF in the presence of added acid shows a similar behaviour than that measured in DMF solution, therefore the reaction mechanism is the same in all studied solvents. The electrochemical behaviour of ALZ in solution of a given solvent in the presence of added acid results similar for both $\left(\mathrm{Na}^{+}\right.$ and $\mathrm{R}_{4} \mathrm{~N}^{+}$) supporting electrolytes (see Figs. $4 \mathrm{a}, 5,8$ ). This behaviour also evidences the interaction of the alkaline cation with the opposite charge species.

\subsection{In the presence of added base}

CVs for ALZ in the solution of the solvents used in this work other than DMF in the presence of high $\mathrm{R}_{\mathrm{KOH}}$ molar ratio $\left(\mathrm{R}_{\mathrm{KOH}}>5\right)$ show a cathodic reversible couple. There is a solvent effect on the potential and current intensity of the cathodic couple in presence of added base (Table 1). In general, the cathodic process occurs at less cathodic potentials for solvents with high $A N$ value (e.g. FM: 40, $\mathrm{MeOH}:$ 41, EtOH: 37) and with ability to form hydrogen bonding, than for solvents of lower value of $A N$ (e.g. DMA: 14, DMSO: 19, HMPA: 11) and without ability to form hydrogen bond. The solvent effect on the redox potential is interpreted based on interaction between solute and solvent such as solute-solvent hydrogen bonding, Lewis acid-base interactions and solute-solvent p-stacking of ring 
systems. The ability to form hydrogen bonding and the high Lewis acidity $(A N)$ of the solvents like $\mathrm{FM}, \mathrm{MeOH}$ and EtOH may favourably stabilize the specie $\left(\mathbf{A}^{\mathbf{*}^{3-}}\right.$, see E6 in Scheme 7$)$ and then the redox couple is observed at less cathodic potential than in solvents with lower $A N$ and without ability to form hydrogen bondings. The hydrogen bond reduces the electron density on the carbonyl oxygen atom(s) and thus increases the electrophilic nature of the aromatic system and stabilizes the anion radical $\mathbf{A}^{\mathbf{0}^{3-}}$ formed during the charge transfer process [43].

A particular electrochemical behaviour is shown by the CVs measured for ALZ in DMA solution in the presence of added base. For intermediate concentrations of added base $\left(\mathrm{R}_{\mathrm{KOH}} \approx 2\right)$, the $\mathrm{CV}$ shows a cathodic process of adsorption on the vitreous carbon electrode in the first cathodic scan, which is detected in the subsequent anodic sweep. This adsorption is affected by the final concentration of the added base and the electrochemical variables such as sweep rate, cathodic potential sweep limit and the time spent in the cathodic potential limit. In Figs. 9 and 8S are shown some examples. The measured CV for ALZ in DMA solution in the absence of base is similar to that measured in DMF. In the presence of added base, for intermediary $\mathrm{KOH}$ concentrations (e.g. $\mathrm{R}_{\mathrm{KOH}} \approx 2$ ), Fig. 9, the anionic intermediate (probably $\mathbf{A H}^{\boldsymbol{*}^{2-}}$ ) generated in the first cathodic scan is strongly adsorbed on vitreous carbon electrode. The corresponding desorption is observed in the subsequent anodic sweep as a wave whose maximum (potential and current intensity and charge) depends on the cathodic potential limit of the sweep and on the time spent in the electrosorption potential zone. During the stopping potential, the surface of the electrode is gradually covered by $\mathbf{A \mathbf { H } ^ { \bullet 2 - }}$ (as $\mathrm{Na}^{+}$salt, with $\mathrm{NaClO}_{4}$ as supporting electrolyte). The electrosorbed species is electro-oxidized on the surface of the electrode during the anodic scan. Therefore, the potential for the electro-oxidation depends on the coverage and prob-

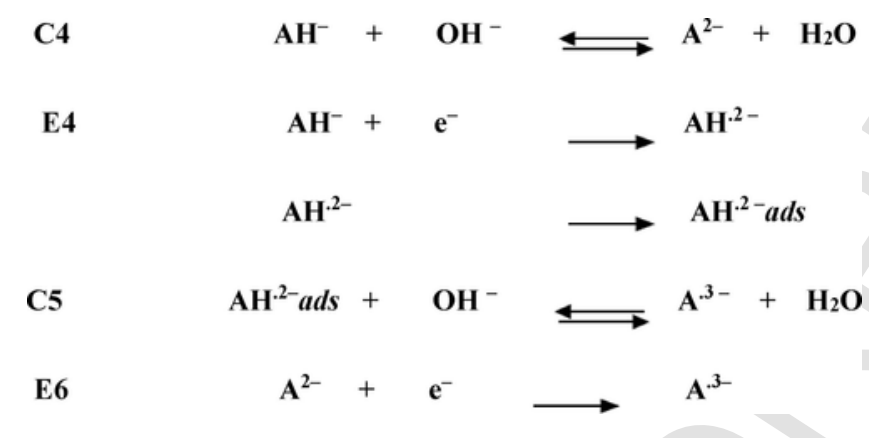

Scheme 7. Mechanism for electro-reduction of ALZ in DMA solution in the presence of added base.

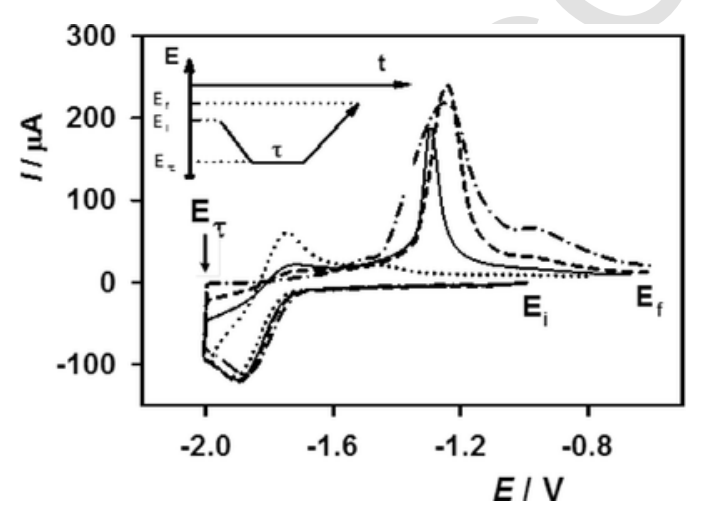

Fig. 9. Cathodic CVs of $5.08 \mathrm{mM} \mathrm{ALZ}$ and $10 \mathrm{mM} \mathrm{KOH}$ in DMA solution, at different times of stay at $-2.0 \mathrm{~V}(\mathbf{E} \tau) .(\bullet \bullet \bullet \bullet): 0 \mathrm{~s} ;(---): 2 \mathrm{~s} ;(-): 5 \mathrm{~s} ;(-\bullet-\bullet): 60 \mathrm{~s} . v$ : $0.200 \mathrm{Vs}^{-1}$; supporting electrolyte: $0.10 \mathrm{M} \mathrm{NaClO}_{4}$. ably on the changes that occur on the surface [44]. For greater concentrations of base $\left(\mathrm{R}_{\mathrm{KOH}}>2\right)$ electrosorption process is not observed, the specie $\mathbf{A} \mathbf{H}^{-}$is transformed in $\mathbf{A}^{\mathbf{2 -}}$ and $\mathbf{A} \mathbf{H}^{\mathbf{*}^{-}}$is not formed. The new proposed reaction mechanism is shown in Scheme 7.

During the cathodic sweep, the amount of adsorbed species [AH $\left.{ }^{-2} \boldsymbol{a d s}\right]$ depends on the time that the electrode stays at the electroadsorption potential zone. For short times, electroadsorption hardly occurs, so only diffusional $\mathbf{A} \mathbf{H}^{\boldsymbol{*}^{2-}}$ oxidation on anodic sweep is observed (Fig. 9, dotted line). For longer times, the electro-oxidation of the adsorbed species is shown by the anodic peak at potentials above $-1.3 \mathrm{~V}$. The extent of adsorption of $\mathbf{A H}^{\mathbf{\bullet}^{2-}}$ also depends on the cathodic potential scan limit (Fig. 8S in Supplementary Material).

\subsubsection{Quinone dyes other than $A L Z$}

The electrochemical parameters Ep and Ip for PP, QZ, ALS and $\mathrm{CA}$ in solution of the different solvents studied are shown in Table 2 (in Supplementary Material). Some CVs as examples are in Figs. 5S, $6 \mathrm{~S}, 7 \mathrm{~S}$ and $10 \mathrm{~S}$ in the Supplementary Material. There is an important solvent effect on the electrochemical behaviour of these dyes in solution. For instance, for PP the number of electro-reduction processes observed in the first cathodic scan is 1 (in TMU, Table 2 in Supplementary Material), 2 (in NMF, Table 2 in Supplementary Material, Fig. 5S and FM, Table 2 in Supplementary Material) and 5 (in DMSO, Table 2, Fig. 10S in Supplementary Material). Experimental observations which deserve some relevant considerations and their rationalizations are summarized below.

a) CVs measured for the dyes in DMSO solution in the absence of added acid or base show some more or less overlapping of the electro-reduction peaks (Table 2, Fig. 10S in Supplementary Material). For example, PP (three acidic phenolic protons) shows five peaks and QZ (four acidic protons) four peaks. The largest number of the protonation equilibria involved and the possible proton transfers are responsible for the detection of those electron transfer processes. The electrochemical (CV) and spectroscopic (UV- vis) behaviour of PP and the other dyes in FM, NMF or TMU solution is similar to the behaviour of ALZ in the same solvents. Some examples are shown in Supplementary Material (Fig. 5S).

b) Peak potentials measured in the presence of added acid (see below, 3.2.2.1. Dyes other than ALZ in the presence of added acid or base) are shifted in the less cathodic direction vs. Ecp $1_{\text {dye,solv }}$ measured in the absence of added acid. There is a solvent effect on the magnitude of the shift (Table 2 in Supplementary Material). Thus, for example, the shift is almost negligible for PP and AC in solution of DMSO solvent, while for AC in FM solution, the shift is ca. $730 \mathrm{mV}$. This behaviour may be rationalized in terms of the dissociation constant of the added acid (TFA) in the different solvents $[33,45]$. The degree of dissociation of TFA is greater in solvents with high dielectric constant $(\varepsilon)$ and $A N$ (e.g. FM, $\varepsilon=109$, $A N=40)$, so that in solution of this type of solvents the potential shift caused by the added acid is greater than the shift observed in solvents with less dielectric constant and $A N$ (e.g. DMSO, $\varepsilon=47$, $A N=19)$.

c) Substitution of one hydrogen atom of $\mathrm{C}_{\mathrm{arom}}-\mathrm{H}$ bond of $\mathrm{ALZ}$ by a sodium salt of the sulfonic acid group $\left(-\mathrm{SO}_{3}{ }^{-} \mathrm{Na}^{+}\right)$as in ALS slightly modifies or does not modify the $\mathrm{CV}$ response of the dye in solution. The negative charge on the sulfonate group dispersed on the three oxygen atoms and the cation $\mathrm{Na}^{+}$compensate the strong electron withdrawing effect of a sulfonic group $\left(-\mathrm{SO}_{3} \mathrm{H}\right)$.

d) Some dyes precipitate in various solvents in the presence of added base (Table 2 in Supplementary Material) probably as a consequence of a competition between the ability of these solvents to 
solvate the species with negative or positive charges (cation of the supporting electrolyte) and the common ion effect responsible for the decrease in the solubility of an ionic species when a soluble compound (supporting electrolyte) containing one of the ions $\left(\mathrm{Na}^{+}\right)$ of the precipitate is added to the solution. Under these conditions no anodic or cathodic peaks are observed in the suitable range of potential. Some examples are showed in Table 1 and in Table 2 and Fig. 6S in Supplementary Material for CA in TMU (dashed-dotted line).

\subsubsection{Dyes other than ALZ in the presence of added acid or base}

The electrochemical behaviour of PP, QZ, ALS and CA dyes is also modified by the addition of an acid or a base. Only one cathodic peak is detected with a sufficient excess of added acid (in all solvents) or added base (in all solvents, except for the insoluble dyes in basic medium, e.g. PP, CA, QZ, see Table 2 in the Supplementary Material). The CVs of PP in NMF solution in the absence and in the presence of added acid or base are shown in Fig. 5S in the Supplementary Material. The electro-reduction in the presence of a sufficient excess of added acid shows only one peak shifted to less cathodic potential respect to the first electro-reduction peak measured in the absence of acid. There is a solvent effect on the magnitude of the shift. For example, for PP in DMSO solution the only peak does not shift, while in FM solution the shift is $+0.45 \mathrm{~V}$ (see Table 2 in Supplementary Material).

The electro-reduction in the presence of sufficient excess of added base shows, in general, only one peak cathodically shifted respect to the peak corresponding to the first electron transfer process measured in the absence of added base. The magnitude of the shift depends on the dye and the solvent. For example, the shift is $0.71 \mathrm{~V}$ for ALS in DMSO solution, while it is $0.53 \mathrm{~V}$ in FM solution (see Table 2 in Supplementary Material).

\subsection{Anodic behaviour of $A L Z$ and the other dyes}

The peaks observed in the anodic sweeps in the CV experiments are related to the electro-oxidation of the phenol moieties of the dye molecules [46]: $\mathbf{A H}_{\mathbf{2}} \leftrightarrow \mathbf{A}+2 \mathrm{H}^{+}+2 \mathrm{e}^{-}$, where $\mathbf{A}$ (see Scheme 3) is the tetracarbonyl compound.

The general electrode reaction mechanism proposed is shown in Scheme 2 . The following aspects are particularly noteworthy and deserve to be discussed.

a) The electro-oxidation reaction of $\mathbf{A H}_{\mathbf{2}}$ in DMF and others solvents is quasireversible (Figs. $4 \mathrm{a}, 5,8$ ) and the reverse reaction seems be the regeneration of $\mathbf{A H}_{\mathbf{2}}$ (dotted line in Fig. 9S in Supplementary Material). This assumption is supported by the fact that in the subsequent cathodic sweep, the current intensity of the peak corresponding to the reduction of $\mathbf{A H}_{\mathbf{2}}$ in DMF $(\mathrm{Ecpl}=-1.19 \mathrm{~V})$ is similar to that measured in the first cathodic sweep (Fig. 9S in Supplementary Material)

b) The production of protons in the electro-oxidation reaction of $\mathbf{A H}_{\mathbf{2}}$ is discovered in the $\mathrm{CV}$ in the subsequent cathodic scan. For instance, for ALZ in DMF solution, the peak corresponding to the electro-oxidation of ALZ in the first anodic sweep is observed at $E a p=+0.68 \mathrm{~V}$, while in the subsequent cathodic sweep, the protons formed in this manner produce a peak prior (called pre-peak) to the corresponding to the first electro-reduction of ALZ molecule (see $\mathbf{C 6}$ and/or $\mathbf{C 8}$ in Scheme 2). The current intensity of the pre-peak increases when the anodic sweep is stopped at a suitably chosen anodic potential (Fig. 9S, stopped potential during $\tau$ : 0,15 and $60 \mathrm{~s}$ ). c) For some dye/solvent systems, the peak potential and current intensity of the electro-oxidation wave are not significantly modified by the addition of acid. Some examples are ALZ in ACN, DMA, DMSO, EtOH or TMU; PP in TMU; QZ, AC and ALS in DMSO, or ALS in TMU (see Tables 1 and 2 in Supplementary Material). This behaviour is related to the extension of the dissociation of the dye molecule. A typical example is the ALZ molecule in ACN, solvent in which ALZ is practically undissociated (Fig. 2). Under these conditions, the addition of acid does not affect the reaction mechanism because the starting reagent is not altered by the presence of the added acid. For this type of solvents the most probably mechanism could be Ea1-Ca1-Ca3-Ea6 (Scheme 2) in the absence and in the presence of added acid. The global process observed at the oxidation wave Eap $=+1.14 \mathrm{~V}$ (Table 1 and Fig. 8) shows two exchanged electrons as predictable.

For other dye/solvent systems in which the dye molecule is highly dissociated even in the absence of added base, as for example ALZ in NMF (Fig. 1) or PP in FM (UV-vis spectra not shown), the reactions Ea3, Ea4 and Ca4 (see Scheme 2) must be added to Ea1-Ca1-Ca3-Ea6 (see Scheme 2), because the electro-oxidation of $\mathbf{A H}^{-}$is also possible.

According to the reaction scheme proposed, the electro-oxidation peak potential depends on the position of the equilibrium C1 (Scheme 2). For example, ALZ in NMF solution (high dissociation acid constant for phenolic-OH groups, Fig. 1) in the absence of acid, the maximum of electro-oxidation wave is observed at $+0.10 \mathrm{~V}$, and it is anodically shifted in $0.49 \mathrm{~V}$ in the presence of added acid.

a) The electro-oxidation of ALZ and the other dyes in solution in the presence of base (e.g. Figs. 5, 4S and 5S) occurs at a lower anodic potential than in the absence of base. The formation of the more easily $\mathbf{A} \mathbf{H}^{-}$and $\mathbf{A}^{\mathbf{2 -}}$ oxidizable species in the solution in the presence of added base (Scheme 8) are responsible for the shift of the electro-oxidation wave.

b) Table 1 includes the $\mathrm{CV}$ parameters $E p$ and current function $\left(c f=I p / v^{1 / 2} \times[\right.$ dye $\left.]\right)$ for intermediate molar ratios $\mathrm{R}_{\mathrm{KOH}}$, e.g. DMSO, $\mathrm{R}_{\mathrm{KOH}} \approx 2$ (anodic scan). For this low $\mathrm{R}_{\mathrm{KOH}}$ value, more peaks are detected in the anodic sweep than those measured when $\mathrm{KOH}$ is added in higher $\mathrm{R}_{\mathrm{KOH}}$ value. Though the effect of the $\mathrm{R}_{\mathrm{KOH}}$ molar ratio on the $\mathrm{CV}$ response has not been studied in great detail, the results show, for example, that only one anodic peak is observed in the CV for ALZ in ACN solution when $\mathrm{R}_{\mathrm{KOH}} \approx 1.4$ (Fig. 8) while in FM solution a $\mathrm{R}_{\mathrm{KOH}} \approx 14$ is required (Fig. $2 \mathrm{~S}$ ). There is a solvent effect on the anodic peak potential obtained for higher $\mathrm{R}_{\mathrm{KOH}}$ values $\left(\mathrm{R}_{\mathrm{KOH}}>5\right)$. The solvent effect again may be rationalized by using the empirical parameter $A N$. The electro-oxidation peak potential for ALZ in the presence of added base and its dependence with the $A N$ parameter for various solvents is shown in Fig. 10. $\mathbf{A}^{\mathbf{2}}$ dianion is slightly stabilized by solvents with small $A N$ values (TMU, HMPA, or DMF). Therefore, $\mathbf{A}^{\mathbf{2 -}}$ is more easily oxidizable and its electro-oxidation peak potential is shifted to less anodic values.
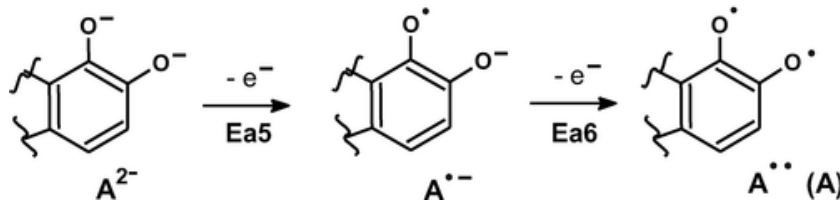

Scheme 8. Electro-oxidation reaction mechanism proposed for ALZ in solution of all studied solvents in presence of base. 


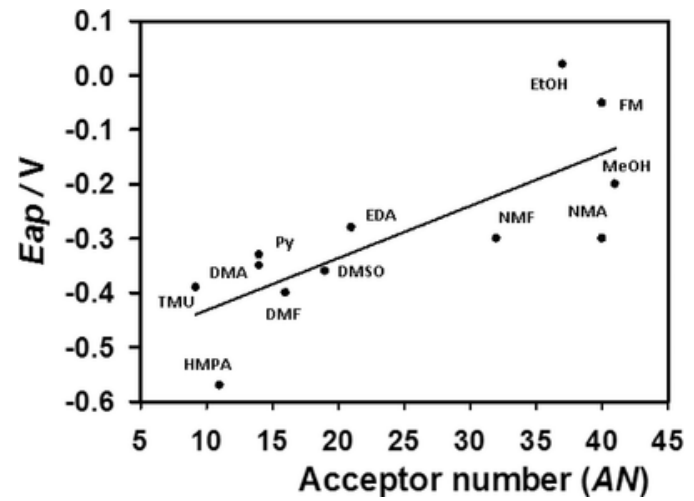

Fig. 10. Dependence of anodic peak potential (Eap) of the ALZ in solution in the presence of added base $\left(\mathrm{R}_{\mathrm{KOH}}>5\right)$ with the Gutmann acceptor number $(A N)$ of the solvents. Supporting electrolyte: $0.1 \mathrm{M} \mathrm{NaClO}_{4}$. Sweep rate: $0.200 \mathrm{Vs}^{-1}$.

\subsection{Stepwise vs. concerted transfer of an electron and a proton}

Finally, a quick view of the stages that make up the general mechanism of electro-reduction of anthraquinone dyes leads us to think about the possibility of the presence of the proton-coupled electron transfer (PCET, reactions involve the concerted transfer of an electron and a proton [47]) [48-50]. Within this scheme, three main cases can be distinguished:

a) Electron transfer and intermolecular proton transfer. It is widely accepted that the first stage of electro-reduction of quinones and related compounds is the formation of the radical anion. Further reactions will depend on a number of factors such as the stability of the radical anion, the medium or the temperature. The initial radical anions corresponding to the anthraquinone dyes studied in our work are sufficiently stable to be detectable by CV or EPR when they are generated by a controlled potential electrolysis as it was measured in our laboratory [51]. From these results it is deduced that the proton transfer from another molecule is relatively slow in the experimental conditions studied, consequently we discard the existence of stages based on PCET reactions.

b) Electron transfer and proton transfer from an external source of protons (added acid). This case is similar to the previous one, but the greater availability of protons is manifested in the increase of the proton transference rate of the acid (TFA) towards the radical anion initially formed. The influence of the solvent when the dye is in the presence of an excess of protons is manifested in the variation of the acid dissociation constant and the proton transfer rate constant of the acid to the electro-generated bases with the nature of the solvent [38]. Therefore the values of these parameters determine the electrochemical parameters, Ep and Ip. Thus, solvents with poor donor capacity (e.g. ACN) produce higher proton transfer rates resulting in a more reversible response and a less cathodic potential. With similar considerations to the previous case, here also we discard mechanisms that involve stages based on PCET reactions.

c) Electron transfer and intramolecular proton transfer. Evidently, the proton transfer (deprotonation) exists in the neutral dye molecule prior to the electron transfer, as Habeeb and Alghanmi point out [52]. Under these conditions the equilibrium position of $\mathbf{A} \mathbf{H}^{-}$ formation will depend on the interaction of $\mathrm{HO}$ at position 2 with the solvent (:S) (see Scheme 9). Thus, the highly donor solvents (FM, HMPA) shift the reaction towards the formation of $\mathbf{A H}^{-}$, as opposed to the poor donor solvents $(\mathrm{ACN})$ in which there is practically no dissociation. This is the scenario in which electron transfer occurs in the electrode/solution interface. The question is whether the formation of the radical anion $\mathbf{A H}_{2}{ }^{-}{ }^{-}$in the first stage influences the intramolecular transfer equilibrium in the neutral molecule $\left(\mathbf{A H}_{\mathbf{2}}\right)$. The presence of the negative charge makes less important the interaction with the solvent described above. But in the presence of donor proton solvents (e.g. $\mathrm{ROH}$ ), the radical anion $\mathbf{A H}_{\mathbf{2}}{ }^{-}$is stabilized through the negative charge. In this case it is feasible to think that intramolecular protonic transfer is not favourable. For this reason we consider that the electron transfer potential position is a result of a complex mixture of several factors: $i$ ) intrinsic stability of the radical anion. The numerous resonant and tautomeric structures describe this stability, ii) the interaction of this charged species with highly accepting

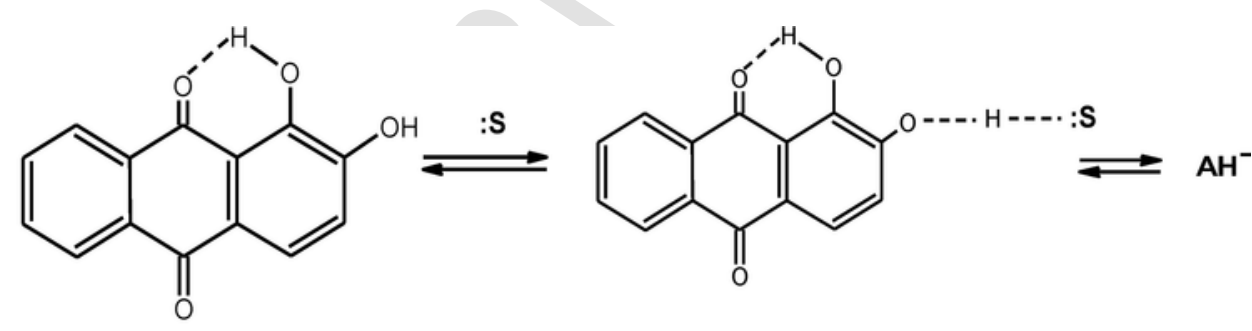<smiles></smiles>

Scheme 9. Proton transfer in the dye neutral molecule prior to the electron transfer. 
solvents $(\mathrm{ROH})$, and $i i i)$ the interaction of the cation of the supporting electrolyte with highly acceptor solvents. The greater or lesser solvation of these cations consequently determines the stabilization of the negative charge in $\mathbf{A H}_{2}{ }^{-}$.

\section{CONCLUSIONS}

Different responses have been observed in the electrochemical characterization of five hydroxyanthraquinone dyes in organic solvent solutions. The electro-reductions/oxidations occur in accessible potential zones. The reactions are strongly influenced by the medium (supporting electrolyte, solvent, and added acid or base). Solvents modify the electrochemical response through their dielectric constant, H-bond ability and charge acceptor/donor properties. These properties modify the dissociation equilibrium of the phenolic-OH and the degree of stabilization of charge species (mainly anions). Solvents with strong acceptor properties favour the dissociation of the phenolic-OH groups, increasing the concentration of the deprotonated species of the dyes in solution. The protonated, parcially o totally deprotonated species are identified by absorption UV-vis spectroscopy.

According to our knowledge, this is the first work that clearly shows that the hydroxyanthraquinone dyes can be found as neutral molecules, partially or totally deprotonated species in solution of numerous non-aqueous solvents in the absence of added acid or base.

The addition of acid to the electrolytic medium affects the electro-reduction process according to the molar ratio $\mathrm{R}_{\mathrm{acid}}=[\mathrm{acid}] /[$ dye $]$ value. The electro-reduction of the dye in the presence of added acid occurs at less cathodic potential than without added acid, being facilitated in this way the process of reduction of the dye. As experimentally measured in the presence of added acid, the increase in $R_{\text {acid }}$ hinders the electro-oxidation, due to the decrease of the concentration of the dissociated forms of the dye, and consequently, the decrease in $\mathrm{R}_{\text {acid }}$ also hinders the electro-reduction of carbonyls by increasing the concentration of the anions.

The electro-reduction of the neutral non-dissociated species has been postulated in the literature for several hydroxyanthraquinones in aqueous basic medium even with a high molar ratio $[\mathrm{NaOH}] /[$ dye $]$. Our voltammetric and spectrophotometric results show that this statement must be rejected. The cathodic process is at more cathodic potentials in the presence of an excess of added base than without base, because the dissociated species are the predominant ones for high molar ratios $\mathrm{R}_{\text {base }}=[$ base] $/[$ dye]. A particular electrochemical behaviour is observed for ALZ in DMA solution with added base in intermediate $R_{\text {base }}$ values. The monodissociated dye is in solution in this experimental condition and its reduction product, the radical-dianion, is electrosorbed on the vitreous carbon electrode.

The electro-oxidation behaviour of the dyes is also influenced by the extension of the acid dissociation of the dye molecule. When the dye molecule is non-dissociated in a given solvent, the addition of acid does not affect the anodic behaviour. On the other hand, for other dye/ solvent systems in which the dye molecule is highly dissociated the electro-oxidation occurs at less anodic potentials and an effect of the added acid is observed in the cyclic voltammogram.

A very important role plays the supporting electrolyte. The presence of alkaline cations allows the CV detection of more charge transfer processes respect to the more inert tetraalkylammonium cation. The relative current intensities of the $\mathrm{CV}$ detected processes in the presence of alkaline cations are also influenced by the above mentioned variables. The study of the effect of the supporting electrolyte on the electrochemical behaviour of the hydroxyanthraquinone dyes reveals the confusion published in the literature that the electro-reduction of the hydroxyquinones proceeds only through the formation of a radical-anion and a dianion.
For comparison with related compounds (9,10-anthraquinone and phenols), it is possible to conclude that the electrochemical reaction products come from the electro-reduction of the carbonyl-quinone groups strongly assisted by phenol moieties, while the electro-oxidation is mainly due to phenolic groups modified by the quinone groups.

A general square reaction scheme, including all the electro-reduction/oxidation processes and the chemical acid-base equilibria, is proposed. Furthermore, the most important reaction routes for particular dye/solvent systems without or with added acid or base are emphasized and rationalized.

\section{Acknowledgements}

This work was financially supported by Consejo Nacional de Investigaciones Científicas y Técnicas (CONICET, CCT LP) and Universidad Nacional de La Plata (UNLP), Facultad de Ciencias Exactas, Departamento de Química and Facultad de Ingeniería, Departamento de Ingeniería Química. M. V. M and J. A. C. are researchers of CONICET and UNLP; M. J. B. and J. F. M. S. are doctoral fellows of CONICET.

\section{Appendix A. Supplementary data}

Supplementary data associated with this article can be found, in the online version, at http://dx.doi.org/10.1016/j.electacta.2017.07.139.

\section{References}

[1] F. Delgado-Vargas, O. Paredes-López, Natural Colorants for Food and Nutraceutical Uses, CRC PRESS, Boca Raton, London, New York, Washington, D.C, 2003, p 43 .

[2] T. Bechtold, R. Mussak (Eds.), Handbook of Natural Colorant, John Wiley \& Sons, Ltd., 2009.

[3] D. Cardon, Le Monde des Teintures Naturelles, Éditions Belin, Paris, 2014

[4] D. Cardon, Natural Dyes. Sources, Tradition, Technology and Science, Archetype Publications, London, 2007.

[5] M.S. Hosseini, M. Asadi, Speciation determination of chromium using 1, 4- diaminoanthraquinone with spectrophotometric and spectrofluorometric methods Anal. Sci. 25 (2009) 807-812, https://doi.org/10.2116/analsci.25.807.

[6] S.S. Mitic, G.Z. Miletic, A.N. Pavlovic, S.B. Tosic, D.S. Velimirovic, Development and Evaluation of a Kinetic-Spectrophotometric Method for Determination of Arginine, J. Chin. Chem. Soc. 54 (2007) 47-54, https://doi.org/10.1002/jccs. 200700009.

[7] M. Chamsaz, M.H.A. Zavar, M.S. Hosseini, Flotation Spectrophotometric Determination of Aluminium with Alizarin, Anal. Lett. 33 (2000) 1625-1633, https:// doi.org/10.1080/00032710008543149.

[8] G.E. Feng, L. Jiang, D. Liu, C. Chen, An Automated Fluid-transport Device for a Microfluidic System, Anal. Sci. 27 (2011) 79-84, https://doi.org/10.2116/ analsci.27.1057.

[9] K. Wedege, E. Dražević, D. Konya, A. Bentien, Organic Redox Species in Aqueous Flow Batteries: Redox Potentials, Chemical Stability and Solubility, Sci. Rep. 6 (2016) 39101, https://doi.org/10.1038/srep39101.

[10] Z. Zhang, H. Yoshikawa, K. Awaga, Monitoring the Solid-State Electrochemistry of $\mathrm{Cu}(2,7-\mathrm{AQDC})(\mathrm{AQDC}=$ Anthraquinone Dicarboxylate $)$ in a Lithium Battery: Coexistence of Metal and Ligand Redox Activities in a Metal-Organic Framework, J. Am. Chem. Soc. 136 (2014) 16112-16115.

[11] C. Miliani, A. Romani, G. Favaro, Acidichromic effects in 1,2-di- and 1,2,4-trihydroxyanthraquinones. A spectrophotometric and Fluorimetric study, J. Phys. Org. Chem. 13 (2000) 141-150, https://doi.org/10.1002/ (SICI)1099-1395(200003)13:3<141:AID-POC220>3.0.CO;2-J.

[12] S. Das, A. Bhattacharya, P.C. Mandal, M.C. Rath, T. Mukherjee, One-electron reduction of 1,2-dihydroxy-9,10-anthraquinone and some of its transition metal complexes in aqueous solution and in aqueous isopropanol-acetone-mixed solvent: a steady-state and pulse radiolysis study, Radiat. Phys. Chem. 65 (2002) 93-100, https://doi.org/10.1016/S0969-806X(01)00451-0.

[13] P. Cysewski, T. Jelinski, M. Przybylek, A. Shyichuk, Color prediction from first principle quantum chemistry computations: a case of alizarin dissolved in methanol, New J. Chem. 36 (2012) 1836-1843, https://doi.org/10.1039/ c2nj40327g.

[14] J. Preat, A. Laurent, C. Michaux, E. Perpete, D. Jacquemin, Impact of tautomers on the absorption spectra of neutral and anionic alizarin and quinizarin dyes, J. 
Mol. Struct. (Theochem) 901 (2009) 24-30, https://doi.org/10.1016/j.theochem. 2008.12.032.

[15] S. Say-Liang-Fat, J.P. Cornard, Al(III) complexation by alizarin studied by electronic spectroscopy and quantum chemical calculations, Polyhedron 30 (2011) 2326-2332, https://doi.org/10.1016/j.poly.2011.06.014.

[16] L. Quinti, N. Allen, M. Edge, B. Murphy, A. Perotti, A study of the luminescent complexes formed by the dye 1, 4-dihydroxyanthraquinone (quinizarin) and Ga(III) and In(III), J. Photochem. Photobiol. A 155 (2003) 93-106, https://doi. org/10.1016/S1010-6030(02)00395-7.

[17] M. Savko, P. Kasackova, P. Gbur, P. Miskovsky, J. Ulicny, Performance of Time Dependent Density Functional Theory on excitations of medium sized molecules - Test on ionic forms of anthraquinone dihydroxy derivatives, J. Mol Struct. (Theochem) 823 (2007) 78-86, https://doi.org/10.1016/j.theochem.2007. 08.032 .

[18] T. Jeliński, P. Cysewski, E. Makarewicz, Application of alizarin colorimetric measurements for quantification of amine extraction by model food simulants from epoxy polymer, Springer Plus 2 (2013) 593, https://doi.org/10.1186/ 2193-1801-2-593.

[19] Z.M. Abou-Gamra, Kinetics of Decolorization of Alizarin Red S in Aqueous Media by Fenton-like Mechanism, Eur. Chem. Bull., 3, 2014, 108-112. DOI: 10.17628/ECB.2014.3.108.

[20] M.V. Cañamares, J.V. García-Ramos, C. Domingo, S. Sanchez-Cortes, Surface-enhanced Raman scattering study of the anthraquinone red pigment carminic acid, Vibrational Spectroscopy 40 (2006) 161-167.

[21] C. Miliani, A. Romani, G. Favaro, Spectrophotometric and fluorimetric study of some anthraquinoid and indigoid colorants used in artistic paintings, Spectrochimica Acta Part A 54 (1998) 581-588.

[22] P.J. Almeidaa, J.A. Rodrigues, A.A. Barros, A.G. Fogg, Voltammetric studies of anthraquinone dyes adsorbed at a hanging mercury drop electrode using fast pulse techniques, Analytica Chimica Acta 385 (1999) 287-293, https://doi.org/ 10.1016/s0003-2670(98)00586-8.

[23] A.M. Faouzi, B. Nasr, G. Abdellatif, Electrochemical degradation of anthraquinone dye Alizarin Red S by anodic oxidation on boron-doped diamond, Dyes and Pigments 73 (2007) 86-89, https://doi.org/10.1016/j.dyepig.2005.10. 013.

[24] C. Saez, M. Panizza, M.A. Rodrigo, G. Cerisola, Electrochemical incineration of dyes using a boron-doped diamond anode, J. Chem. Technol. Biotechnol. 82 (2007) 575-581, https://doi.org/10.1002/jctb.1703.

[25] T. Bechtold, C. Fitz-Binder, A. Turcanu, Electrochemical characteristics and dyeing properties of selecte 9,10 -anthraquinones as mediators for the indirect cathodic reduction of dyes, Dyes and Pigments 87 (2010) 194-203, https://doi org/10.1016/j.dyepig.2010.03.026.

[26] T. Grygar, S. Kuckova, D. Hradil, D. Hradilova, Electrochemical analysis of natural solid organic dyes and pigments, J. Solid State Electrochem. 7 (2003) 706-713, https://doi.org/10.1007/s10008-003-0380-1.

[27] J.A. Caram, J.F. Martínez Suárez, A.M. Gennaro, M.V. Mirífico, Electrochemical behaviour of methylene blue in non-aqueous solvents, Electrochim. Acta 164 (2015) 353-363, https://doi.org/10.1016/j.electacta.2015.01.196.

[28] D.E. Danly, J.H. King, Industrial Electrorganic Chemistry, in: H. Lund, M.M. Baizer (Eds.), Organic Electrochemistry. An introduction and a guide, 3rd ed., Marcel Dekker Inc., New York, Basel, Hong Kong, 1991, pp. 1285-1336, Ch. 31.

[29] P.S. Guin, S. Das, P.C. Mandal, Electrochemical Reduction of Quinones in Different Media: A Review, Int. J. Electrochem. Sci. (2011) 22, https://doi.org/10. 4061/2011/816202, 816202 and references therein.

[30] D.D. Perrin, W.L.F. Armarego, Purification of Laboratory Chemicals, Butterworth-Heinemann Linacre House, Jordan Hill, Oxford OX2 8DP, Oxford 1996-2000.

[31] C. Reichardt, T. Welton, Solvents and Solvent Effects in Organic Chemistry, 4th ed., Wiley-VCH Verlag GmbH \& Co. KGaA, 2011.

[32] A.J. Fry, R.G. Reed, Electrochemical reduction of imines in dimethylformamide, J. Am. Chem. Soc. 91 (1969) 6448-6451, https://doi.org/10.1021/ja01051a045.

[33] M.V. Mirífico, J.A. Caram, E.J. Vasini, Electroreduction of 3,4-diphenyl-1,2,5 thiadiazole1,1-dioxide in acetonitrile solution and reactions with proton donors,
Electrochim. Acta 36 (1991) 167-171, https://doi.org/10.1016/ 0013-4686(91)85197-F.29.

[34] S.K. Ling-Chuna, P.J.I. Runciman, K.D. Sales, J.H.P. Utley, Electro-organic reactions. Part 34. Kinetic basicities of some electrogenerated organic dianions and the competition between protonation and reproportionation, J. Electroanal. Chem. 250 (1988) 373-384, https://doi.org/10.1016/0022-0728(88)85177-5.

[35] J.A. Caram, M.V. Mirífico, E.J. Vasini, Electrochemistry of 3,4-diphenyl-1,2,5-thiadiazole 1,1-dioxide (I) and its derivatives in ethanol-acetonitrile solutions and interactions of the dianion of I with metal cations, Electrochim. Acta 39 (1994) 939-945, and references therein.

[36] T. Komura, S. Isogai, T. Yamaguchi, K. Takahashi, Voltammetric behavior of 1, 2-dihydroxyanthraquinones attached to glassy carbon electrodes and their surface complexation with copper, J. Electroanal. Chem. 490 (2000) 70-78, https:// doi.org/10.1016/S0022-0728(00)00235-7.

[37] K.R. Mahanthesha, B.E. Kumara Swam, U. Chandra, Y.D. Bodke, K.V. Kumar Pai, B.S. Sherigara, Cyclic Voltammetric Investigations of Alizarin at Carbon Paste Electrode using Surfactants, Int. J. Electrochem. Sci. 4 (2009) 1237-1247.

[38] A.J. Bard, L.R. Faulkner, Electrochemical methods: fundamentals and applications, Wiley, New York, 2001, p. 472.

[39] A. Doménech-Carbó, M.T. Doménech-Carbó, M.C. Saurí-Peris, J.V. Gimeno-Adelantado, F. Bosch-Reig, Electrochemical identification of anthraquinone-based dyes in solid microsamples by square wave voltammetry using graphite/polyester composite electrodes, Anal. Bioanal. Chem. 375 (2003) 1169-1175, https://doi.org/10.1007/s00216-002-1742-8.

[40] J. Jover, R. Bosque, J. Sales, Neural Network Based QSPR Study for Predicting pKa of Phenols in Different Solvents, QSAR Comb. Sci. 26 (2007) 385-397, https://doi.org/10.1002/qsar.200610088.

[41] J.A. Riddick, W.B. Bunger, Organic solvents, Techniques of Chemistry, vol. 2, Wiley Interscience, New York, 1970, 3th third.

[42] R. Schmid, Effect of Solvent on Chemical Reactions and Reactivity, in: G. Wypych (Ed.), Handbook of Solvent, Chem. Tec. Publishing, Toronto, Ontario M1E 1C6, Canada, 2001, p. 737.

[43] Davood Ajloo, Behnaz Yoonesi, Ahmad Soleymanpour, Solvent Effect on the Reduction Potential of Anthraquinones Derivatives, The Experimental and Computational Studies, Int. J. Electrochem. Sci. 5 (2010) 459-477.

[44] P.A. Christensen, A. Hamnett, Techniques and Mechanisms in Electrochemistry, Blackie Academic \& Professional, Glasgow, 1994, Ch. 3.

[45] R.S. Nicholson, I. Shain, Theory of Stationary Electrode Polarography, Anal. Chem. 36 (1964) 706-723, https://doi.org/10.1021/ac60210a007.

[46] P.S. Guin, S. Das, P.C. Mandal, Electrochemical Reduction of Sodium 1, 4-dihydroxy-9, 10-anthraquinone-2-sulphonate in Aqueous and Aqueous DimethylFormamide Mixed Solvent: A Cyclic Voltammetric Study, Int. J. Electrochem. Sci. 3 (2008) 1016-1028.

[47] J.M. Mayer, Proton-Coupled Electron Transfer: A Reaction Chemist's View, Annu. Rev. Phys. Chem. 55 (2004) 363-390.

[48] J.M. Mayer, I.J. Rhil, Thermodynamics and kinetics of proton-coupled electron transfer: stepwise vs. concerted pathways, Biochimica et Biophysica Acta 1655 (2004) 51-58.

[49] C. Costentin, C. Louault, M. Robert, The electrochemical approach to concerted proton-electron transfers in the oxidation of phenols in water, in: J.-M. Saveánt (Ed.), Proceedings of the National Academy of Science of the United Stated of America (PNAS) 106 (2009) 18143-18148, doi: 10.1073.

[50] J.J. Warren, T.A. Tronic, J.M. Mayer, The Thermochemistry of Proton-Coupled Electron Transfer Reagents and its Implications, Chem Rev. 110 (2010) 6961-7001.

[51] J.F. Martínez Suárez, Comportamiento electroquímico de colorantes antraquinónicos, azul de metileno, y compuestos afines en solución de solventes no acuosos, National University of La Plata (UNLP), Buenos Aires, Argentina, 2017, Doctoral Thesis.

[52] M.M. Habeeb, R.M. Alghanmi, Spectrophotometric Study of Intermolecular Hydrogen Bonds and Proton Transfer Complexes between 1,2-Dihydroxyanthraquinone and Some Aliphatic Amines in Methanol and Acetonitrile, J. Chem. Eng. Data 55 (2010) 930-936. 